Verónica Norando, Comunismo, Género y movimiento obrero: un estado de la cuestión, Izquierdas, 30, Octubre 2016:26-64

\title{
Comunismo, Género y movimiento obrero: un estado de la cuestión
}

\author{
Feminism, Gender and labor movement: a state of matter
}

\author{
Verónica Norando*
}

Resumen: En este trabajo nos proponemos hacer un estado de la cuestión sobre comunismo, género y movimiento obrero en la Argentina, sobre todo en la primera mitad del siglo XX. Al mismo tiempo, proponemos articular un marco teóricometodológico que aúne los estudios de género y la historia social desde una perspectiva que incluya en el análisis de clase, las relaciones de género como constituyentes de la experiencia de los trabajadores y las trabajadoras en la Argentina.

Palabras clave: Clase, Género, Movimiento obrero, Comunismo

\begin{abstract}
In this paper we propose to do a state of the question of communism, gender and labor movement in Argentina, especially in the first half of the twentieth century. At the same time propose a theoretical and methodological framework that combines gender studies and social history from a perspective that includes the analysis of class, gender relations as constituents of the experience of workers and women workers in Argentina.
\end{abstract}

Keywords: Class, Gender, Labor movement, Communist

Recibido: 8 junio 2016

Aceptado: 12 agosto 2016

* Dra. En historia, nacionalidad Argentina. Es investigadora del Instituto Interdisciplinario de Estudios de Género (IIEGE) de la Facultad de Filosofía y Letras de la Universidad de Buenos Aires con beca del Consejo Nacional de Investigaciones Científicas y Técnicas (CONICET). Correo electrónico: norandoveronica@gmail.com 


\section{Introducción}

Desde los comienzos de la expansión de la industria en la Argentina, la participación de las mujeres, como mano de obra, en el mundo del trabajo, ha sido muy importante. ${ }^{1}$ Desde fines del siglo XIX, estas trabajadoras han tenido una activa militancia, sindical y política. Al mismo tiempo, las organizaciones de izquierda del movimiento obrero -tanto anarquistas como socialistas y comunistas- han interpelado, de una u otra manera, al sector femenino de la clase obrera. Así, en la Argentina el Partido Comunista (PC), desde sus inicios en la década del 20, ha tenido la intención de insertarse en el mundo de las trabajadoras y, en mayor o menor medida, lo ha logrado, dependiendo de la época y el sector laboral que se tratase.

Desde mediados de la década del 20, entonces, y hasta el surgimiento del peronismo (19431945), el comunismo en la Argentina aumentó su ascendente dentro del movimiento obrero. Además, tuvo una presencia tan significativa (a nivel social, cultural y político) en el país ${ }^{2}$ que se puede hablar de una dinámica que proletarizó la cultura. ${ }^{3}$ Durante ese período constituyó múltiples instituciones culturales y políticas en el seno de la clase obrera: bibliotecas, clubes, agrupaciones juveniles, asociaciones de inmigrantes, ligas antiimperialistas, antiguerras y antifascistas, distintos organismos de solidaridad, etc. El PC organizó a militantes, coordinó un extenso entramado de agitación y propaganda y condujo conflictos gremiales trascendentales. Según Hernán Camarero: "Se convirtió en la organización más importante del proletariado industrial, superior a las otras corrientes con las que venía disputando espacios (anarquistas, socialistas y sindicalistas)". 4

Si esto fue así, se debe, en parte, a que el PC y sus militantes le prestaron atención a la situación obrera femenina, dándole importancia a su especificidad. Durante ese período, el partido se insertó en el abigarrado y complejo mundo del proletariado industrial argentino.

\footnotetext{
${ }^{1}$ Rocchi, Fernando, "Concentración de capital, concentración de mujeres. Industria y trabajo femenino en Buenos Aires 1890-1930”, en Gil Lozano, Fernanda., Pita, Valeria S. e Ini, María G. (comps.), Historia de las mujeres en la argentina, t. II: Siglo XX, Buenos Aires, Taurus, 2000.

2 Camarero, Hernán, A la conquista de la clase obrera. Los comunistas y el mundo del trabajo en la Argentina, 1920-1935, Buenos Aires, Siglo XXI, 2007, p. XIII.

${ }^{3}$ Altamirano, Carlos, Peronismo y cultura de izquierda, Buenos Aires, Temas, 2001; Camarero, Hernán, "El Partido Comunista argentino y sus políticas en favor de una cultura obrera en las décadas de 1920 y 1930 ", Pacarina del Sur. Revista de pensamiento crítico latinoamericano, vol. II, México, 2011, pp. 1-31; Browarnik, Graciela y Benadiba, Laura, “Artistas militantes en el Partido Comunista argentino", Historia, Antropología y Fuentes Orales, $\mathrm{N}^{\circ}$ 37, 2007, pp. 89-99; Becerra, Marina, "Maternidad y ciudadanía en la Argentina de principios del siglo XX: un análisis de la autobiografía de María Rosa Oliver", $A$ Contracorriente, vol. 10, 2013, pp. 202-218; Bertúa, Paula, “Artistas y escritoras en la prensa cultural antifascista", Primeras Jornadas de Género y Trayectorias antifascistas, UNLP, 2013; Camarero, Hernán, "La izquierda como objeto historiográfico. Un balance de los estudios sobre el socialismo y el comunismo en la Argentina", Nuevo Topo. Revista de historia y pensamiento crítico, N 1, Buenos Aires, 2005, pp. 77-99.

${ }^{4}$ Camarero, Hernán, A la conquista..., op. cit., p. XIII (bastardillas en el original).
} 
En este proceso, sus militantes -tanto varones como mujeres-colaboraron en la activación política entre las trabajadoras, y desplegando distintas estrategias, se sumergieron en la problemática obrera femenina. Llevaron adelante y contribuyeron a sostener organizaciones específicas de mujeres, tanto a nivel sindical como partidario. De hecho, uno de los objetivos principales del PC en relación con el mundo obrero, hacia mediados de la década del 30, fue la organización de las trabajadoras.

En la década del 30 se vivió una atmósfera de múltiples transformaciones, tanto a nivel político como económico. Por un lado, significó el fin de la experiencia democrática comenzada en 1916, con la que constituiría la primera de las reiteradas intervenciones militares cuyos signos serían la inestabilidad política, lo que marcó a su vez un ambiente sumamente represivo para el movimiento obrero. Por otro lado, luego de la crisis se da inicio a un proceso de industrialización sustitutiva, que traería grandes transformaciones en la composición de la clase trabajadora argentina. En este contexto, el mundo del trabajo femenino se extendió de tal modo que abarcó una extensa variedad de actividades y se registra un incremento de la participación femenina en los sectores secundario y terciario de la economía urbana. ${ }^{5}$

A pesar de que el porcentaje de mujeres trabajadoras ocupadas en las distintas ramas de la industria creció levemente, su concentración fue mayor en las industrias en crecimiento (como la industria química, el caucho, la alimentación y la textil). Si bien hacia fines del siglo XIX más de la mitad de las trabajadoras se encontraba en "personal de servicio"6 y casi el $36 \%$ se empleaba en el sector industrial, medio siglo después las mujeres ubicadas en el servicio doméstico habían disminuido y la industria concentraba la mayor parte de la fuerza de trabajo femenina, el $40 \%{ }^{7}$ Dentro de la industria, el sector que mayor cantidad de mano de obra femenina concentraba era el textil. Contabilizando su mano de obra a nivel global, el $63 \%$ eran mujeres. ${ }^{8}$

Además, éste fue uno de los sectores industriales más pujantes de la época. La expansión se originó, en alguna medida, por la aplicación de políticas públicas que favorecieron esta

\footnotetext{
${ }^{5}$ Queirolo, Ggraciela, "Mujeres que trabajan: una revisión historiográfica del trabajo femenino en la Ciudad de Buenos Aires (1890-1940)", )", Nuevo Topo. Revista de historia y pensamiento crítico, $\mathrm{N}^{\circ} 3$, Buenos Aires, 2006, pp. 29-49, disponible en http://www.academia.edu/12934730/Mujeres que trabajan una revisi\%C3\%B3n historiogr\%C3\%A1fica d el trabajo femenino en la ciudad de Buenos_Aires 1890-1940 ; fecha de consulta: 10 de noviembre de 2015.

${ }^{6}$ Pérez, Inés, "Un «régimen especial» para el servicio doméstico. Tensiones entre lo laboral y lo familiar en la regulación del servicio doméstico en la Argentina, 1926-1956", en El trabajo doméstico entre regulaciones formales e informales. Miradas desde la historia y la sociología, IDES, Serie proyectos de investigación, 2015.

${ }^{7}$ Nari, María M.A. Políticas de maternidad y maternalismo político. Buenos Aires, 1890-1940, Buenos Aires, Biblos, 2004; Queirolo, Graciela, "Las mujeres y los niños en el mercado de trabajo urbano (Buenos Aires, 1890-1940)", en Recalde, H.E. (coord.), Señoras, universitarias y mujeres (1910-2010), Buenos Aires, Grupo Editor Universitario, 2010, pp. 17-37.

${ }^{8}$ Industria textil. Capacidad normal de trabajo de los obreros de la industria textil, especialmente mujeres y menores, Departamento Nacional del Trabajo (DNT), Buenos Aires, 12 de junio de 1939.
} 
Verónica Norando, Comunismo, Género y movimiento obrero: un estado de la cuestión, Izquierdas, 30, Octubre 2016:26-64

rama de la industria ${ }^{9}$ y por una protección aduanera que contribuyó a la expansión e instauración de empresas tanto nacionales como extranjeras. Esta situación coincidió con el contexto de la crisis económica mundial y las perturbaciones en el comercio internacional, que intensificaron el proceso de sustitución de importaciones. ${ }^{10}$

Este crecimiento dio lugar a un aumento de las personas ocupadas ${ }^{11} \mathrm{y}$ de las luchas del movimiento obrero industrial. De hecho, hacia mediados de la década del 30 se produjo un aumento en el conflicto social. ${ }^{12}$ Sin duda, los hechos más significativos fueron las huelgas de la construcción que derivaron en la huelga general de 1936. El desarrollo de la Federación Obrera Nacional de la Construcción (FONC) y la huelga de la construcción han recibido un amplio tratamiento en la historiografía, en el que se destacan los trabajos de Hernán Camarero y Nicolás Iñigo Carrera. ${ }^{13}$ Sin embargo, como indican Débora D’Antonio y Omar Acha, otros conflictos de la época han pasado inadvertidos, como es el caso de las huelgas de las y los trabajadores textiles. ${ }^{14}$ Según las estadísticas del Departamento Nacional del Trabajo (DNT), en 1936 se produjeron 109 huelgas, de las cuales 37 fueron en la construcción y 25 en textiles y confección. Del conjunto de las huelgas del año 1936, el $33,9 \%$ corresponden a la construcción mientras que textiles y confección se ubican en el segundo, lugar con el 22,9\%, lo que indica la alta conflictividad del sector. ${ }^{15}$

La participación de las obreras en estas luchas está documentada en el material que hemos utilizado en estudios prescedentes. Las trabajadoras tenían amplia participación en las manifestaciones de protesta del sector y se enfrentaron a despidos, golpes y detenciones por participar en los distintos conflictos.

\footnotetext{
${ }^{9}$ Lobato, Mirta Z., Historia de las trabajadoras en la Argentina (1869-1960), Buenos Aires, Edhasa, 2007, p. 51.; Korol, JuanC. y Belini, Claudio, Historia económica de la Argentina en el siglo XX, Buenos Aires, Siglo XXI, 2012.

${ }^{10}$ Dorfman, Adolfo, Historia de la industria Argentina, Santiago de Chile, Hispamérica, 1970, pp. 347-350; Colman, Oscar "La industria textil y la reconversión extensiva del sector industrial argentino", Ciclos, N 2, Buenos Aires, 1992, pp. 123-155.

${ }^{11}$ Di Tella, Torcuato S., “La Unión Obrera Textil. 1930-1945”, Desarrollo Económico, N 129, Buenos Aires, 1993, pp. 110-136, 3, disponible en

http://repositoriorecursos-download.educ.ar/repositorio/Download/file?file id=b8ba91b2-7a09-11e1-82f0ed15e3c494af

${ }^{12}$ Murmis Miguel y Portantiero, Juan C., Estudios sobre los orígenes del peronismo, Buenos Aires, Siglo XXI, 1971; Camarero, Hernán, A la conquista..., op. cit.; Iñigo Carrera, Nicolás, La estrategia de la clase obrera, 1936, Buenos Aires, Ediciones Madres de Plaza de Mayo, 2004.

13 Camarero, Hernán, "Un sindicato comunista antes del advenimiento del peronismo: el caso de la Federación Obrera Nacional de la Construcción (FONC)", Actas de las XII Jornadas Interescuelas/Departamentos de Historia, Universidad Nacional del Comahue, Bariloche, 2009; Camarero, Hernán, A la conquista..., op. cit.; Durruty, Celia, "La Federación Obrera de la Construcción”, en Di Tella, T.S. (coord.), Sindicatos eran los de antes, Buenos Aires, Biblos-Fundación Simón Rodríguez, 1993; Iñigo Carrera, Nicolás, La estrategia de la ..., op. cit.

${ }^{14}$ D’Antonio, Débora y Acha, Omar, "La clase obrera «invisible»: imágenes y participación sindical de las obreras a mediados de la década de 1930 en Argentina”, en Halperín, Paula y Acha, Omar (coords.), Cuerpos, géneros e identidades, Buenos Aires, Signo, 2000.

${ }^{15}$ Boletín informativo, DNT, año XYX, Época VI, N²06-207, Buenos Aires, Victoria 618, marzo y abril de 1937.
} 
En los últimos años se ha producido una diversificación en los estudios que hacen eje en la intersección entre comunismo y movimiento obrero, así como también surgieron investigaciones provenientes de los estudios de género y la historia social que nos brindan claves para entender este proceso. Aquí vamos a repasar la bibliografía sobre comunismo, movimiento obrero y género tratando de establecer la relación que nos permita trazar las presencias y ausencias, y a partir de ello avanzar en una interpretación que aporte a la historiografía sobre esta temática. Ante el obstáculo que constituye la ausencia de estudios sobre la militancia obrera femenina en relación con el comunismo haremos un balance de la bibliografía por partes. Así, en un primer momento, examinaremos la literatura sobre la historia del comunismo en la Argentina y su inserción en las organizaciones de la clase obrera, para luego pasar revista, en el apartado siguiente, a los que versan sobre el comunismo y la acción gremial de las mujeres.

\section{Comunismo y movimiento obrero: un balance historiográfico}

Las primeras referencias al comunismo en la Argentina fueron las historias del movimiento obrero escritas a lo largo de varios años por líderes gremiales. ${ }^{16}$ Estas obras constituyen un género propio dentro del campo historiográfico: la historia militante. Ellas delinearon, con rasgos heroicos, la historia de los trabajadores con el fin utilitario de reivindicar sus propias orientaciones políticas. Dentro de esta producción, el único que abordó de manera sistemática la presencia comunista entre los trabajadores fue Rubens Iscaro, aunque autores como Camarero han señalado que magnificó el papel de los comunistas y que, también, justificó posiciones políticas con argumentos forzados. ${ }^{17}$

La temática cobra mayor relevancia cuando prestamos atención a un campo que ha sido denominado la historia oficial del PC. ${ }^{18}$ Son textos referidos al pasado del partido y su relación con los trabajadores elaborados por sus propios miembros. ${ }^{19}$ Se trata de obras redactadas por miembros del partido, que poseen un estilo propagandístico y muy escaso sentido crítico en el tratamiento de los temas. Hernán Camarero afirma que estos autores han sido responsables de tergiversaciones no sólo de los hechos sino también de los

\footnotetext{
${ }^{16}$ Oddone, Jacinto, Historia del socialismo argentino, Buenos Aires, CEAL, 1983; Iscaro, Rúbens, Historia del movimiento sindical, Buenos Aires, Fundamentos. Versión anterior: (1958), Origen y desarrollo del movimiento sindical argentino, Buenos Aires, Anteo, 1973; Marotta, Sebastián, El movimiento sindical argentino. Su génesis y desarrollo, t. III, Buenos Aires, Lebera, 1975; Abad de Santillán, Diego, La FORA. Ideología y trayectoria del movimiento obrero revolucionario argentino, Buenos Aires, Proyección, 1971.

${ }^{17}$ Camarero, Hernán, A la conquista ...op.cit.

${ }^{18}$ Camarero, Hernán, "Antiguas controversias, nuevos enfoques: clase obrera, sindicalismo y comunismo en la Argentina durante la primera mitad del siglo XX. Un estado de la cuestión", PolHis, año 6, No 11, Buenos Aires, 2013, pp. 129-146.

${ }_{19}$ Marianetti, Benito, Argentina. Realidad y perspectivas, Buenos Aires, Platina, 1964; Paso, Leonardo, Historia de los partidos políticos en la Argentina (1900-1930), Buenos Aires, Directa, 1983; Arévalo, Oscar, El partido comunista, Buenos Aires, CEAL, 1983; Fava, Athos, Qué es el partido comunista, Buenos Aires, Sudamericana, 1983.
} 
documentos. ${ }^{20}$ A nivel general, esta bibliografía trata de reafirmar permanentemente que las estrategias y los posicionamientos del PC con respecto a la política nacional y al modo de inserción en el movimiento obrero fueron acertados.

Una contribución significativa la constituyen las biografías, autobiografías y memorias de los cuadros del PC o sobre ellos. ${ }^{21}$ Estas historias de vida, a pesar de estar escritas desde un lugar autoproclamatorio, ofrecen descripciones relevantes sobre cómo se procesó la experiencia comunista entre los trabajadores y dejan entrever la mirada de los acontecimientos que tuvieron sus propios partícipes. Mirta Zaida Lobato y Leandro Gutiérrez han analizado este género a partir de Crónicas proletarias, de José Peter. Los autores plantean que estas obras son narradas como gestas de abnegación, sufrimiento y entrega a la causa, pero al mismo tiempo resaltan su importancia puesto que recrean experiencias militantes relevantes para el estudio de los conflictos y la experiencia obrera en general. ${ }^{22}$

Otro corpus bibliográfico que hay que tener en cuenta en los estudios sobre comunismo, y su relación con el sindicalismo y el movimiento obrero, es el producido por la llamada izquierda nacional o nacional-populismo de izquierda, cuyos autores más representativos fueron Jorge Abelardo Ramos y Rodolfo Puiggrós, pero también podemos destacar, en esta perspectiva, a Juan José Hernández Arregui. ${ }^{23}$ Si bien el único que ha abordado la historia del PC directamente ha sido Ramos, esta corriente, en general, le ha dado mucha relevancia al comunismo en sus estudios. Camarero esbozó un interesante planteo sobre la trascendencia de esta bibliografía a nivel historiográfico. ${ }^{24} \mathrm{El}$ autor plantea que, así como las visiones que hemos analizado anteriormente (la historia militante y la historia oficial del PC) realzaron positivamente la intervención del comunismo en el movimiento obrero, los autores de la izquierda nacional buscaron, por el contrario, impugnar tal inserción. Esta corriente quiso exponer permanentemente las equivocaciones del PC "atribuyéndole un vicio de origen o una desviación irreversible en determinado momento de su historia". ${ }^{25}$ Según el autor, en estas visiones, el análisis quedó obturado por una perspectiva impugnadora.

\footnotetext{
${ }^{20}$ Camarero, Hernán, “Antiguas controversias, nuevos enfoques...”, op. cit., p. 132.

${ }^{21}$ Peter, José, Crónicas proletarias, Buenos Aires, Esfera, 1968; Burgas, Miguel, El primer diputado comunista. Año 1924, Buenos Aires, Anteo, 1985; Contreras, Miguel, Memorias, Buenos Aires, Testimonios, 1978; entre otros.

${ }^{22}$ Gutiérrez, Leandro y Lobato, Mirta Z., "Memorias militantes: un lugar y un pasado para los trabajadores argentinos", Entrepasados, № 3, Buenos Aires, 1992, pp. 25-49.

${ }^{23}$ Ramos, Jorge A., El Partido Comunista en la política argentina, Buenos Aires, Coyoacán, 1962; Puiggrós, Rodolfo, Las izquierdas y el problema nacional, Buenos Aires, Cepe, 1973; Hernández Arregui, Juan J., La formación de la conciencia nacional (1930-1960), Buenos Aires, Plus Ultra, 1960-1973.

${ }^{24}$ Camarero, Hernán, A la conquista..., op. cit., pp. XLIV-XLV; Camarero, Hernán, “Apogeo y eclipse de la militancia comunista en el movimiento obrero argentino de entreguerras. Un examen historiográfico y algunas líneas de interpretación”, en Ulianova, O. (ed.), Redes políticas y militancias. La historia política está de vuelta, Santiago, Universidad de Santiago de Chile-Ariadna, 2009, pp. 150-152; Camarero, Hernán, "Antiguas controversias, nuevos enfoques...", op. cit., pp. 133-134.

${ }^{25}$ Camarero, Hernán, “Antiguas controversias, nuevos enfoques...”, op. cit., p. 134.
} 
Hasta aquí, la bibliografía que hemos analizado no pertenece al mundo académico. En la década del 60, desde la disciplina de la sociología, y enmarcada en una investigación sobre los orígenes del peronismo, surgió la perspectiva de Gino Germani. Este autor es un punto de referencia ineludible. Sus conclusiones confluyeron con las visiones que descalificaron la presencia comunista en el movimiento obrero. En sus investigaciones, se presentó a la Argentina industrial emergente en los años 30 desde el prisma de un corte abrupto entre una "vieja" y una "nueva" clase obrera. La primera, en su mayoría descendiente de inmigración europea, aparecía inclinada a ideologías de clase, portaba un carácter autónomo y poseía una extensa experiencia industrial y sindical; mientras la segunda, reclutada en la inmigración interna desde las provincias rurales, se mostraba heterónoma y privada de aquella experiencia de clase. Por esta razón, Germani encontraba que estos nuevos contingentes laborales habrían sido totalmente esquivos a los partidos de clase como el PC y el Partido Socialista (PS) y se habrían convertido en una masa en disponibilidad para el ejercicio de proyectos autoritarios y demagógicos como el encarnado por Juan Domingo Perón desde $1943 .^{26}$

Desde principios de la década del 70, varios estudios fueron dialogando con aquellas visiones y erosionaron los contornos de la supuesta antinomia entre "vieja" y "nueva" clase obrera al destacar la existencia de fuertes interrelaciones entre esos dos actores que Germani oponía con tanto énfasis. ${ }^{27}$ Estos autores redescubrieron la inserción del comunismo en el movimiento obrero, aunque no abordaron específicamente esta experiencia.

Hacia finales del siglo XX y principios del XXI fueron publicados varios estudios que abordaron globalmente el movimiento obrero pre-peronista y se sumaron a los trabajos de Miguel Murmis y Juan Carlos Portantiero, Juan Carlos Torre y Hugo Del Campo. En ellos se hizo frecuente el señalamiento a la inserción lograda por el PC en el sindicalismo industrial de los años $30 .{ }^{28}$ De estos estudios, el único que prestó atención sistemática a la Unión Obrera Textil (UOT) fue el de Torcuato Di Tella (en su obra de 1993) pero el foco estuvo puesto en la dirigencia del gremio y en la actitud hacia Perón. Todos estos estudios tendieron a concentrarse en la descripción y en el análisis de las tácticas políticas generales que el PC desplegó en las instancias directivas del sindicalismo y en sus disputas con las otras corrientes. Aunque estos trabajos se centraron en el período 1935-1945 y examinaron los derroteros de la UOT, sólo lo hicieron tangencialmente y alcanzaron a esbozar las tácticas políticas generales que el PC tuvo en las instancias directivas del sindicalismo en sus disputas con las otras corrientes. No estudiaron específicamente a los gremios

\footnotetext{
${ }^{26}$ Germani, Gino, Política y sociedad en una época de transición. De la sociedad tradicional a la sociedad de masas, Buenos Aires, Paidós, 1962.

${ }^{27}$ Murmis, Miguel y Portantiero, Juan C., Estudios sobre los..., op. cit.; Torre, Juan C., La vieja guardia sindical y Perón. Sobre los orígenes del peronismo, Buenos Aires, Razón y Revolución, 1990; Del Campo, Hugo, Sindicalismo y peronismo. Los comienzos de un vínculo perdurable, Buenos Aires, CLACSO, 1983.

${ }^{28}$ Horowitz, Joel, "Ideologías sindicales y políticas estatales en la Argentina, 1930-1943", Desarrollo Económico, XXIV, Buenos Aires, 1984; Korzeniewicz, Roberto, "Las vísperas del peronismo. ...", op. cit.; Di Tella, Torcuato S., "La Unión Obrera...”, op. cit.
} 
comunistas (a excepción de Di Tella, que, como mencionamos, lo hizo parcialmente) ni las características de la acción del partido en el mundo laboral (sobre todo en los momentos de conflicto) así como tampoco el tipo de lazo que se estableció entre el partido y los sindicatos. Tampoco se investigaron las concepciones que animaron esa ligazón, así como los recursos organizacionales que se pusieron en juego, porque lo que intentaban explicar era el surgimiento del peronismo.

En la primera década del siglo XXI, comenzaron a surgir una serie de investigaciones sobre los trabajadores y el movimiento obrero argentino. ${ }^{29}$ Aquí vamos a destacar dos de estas investigaciones, que son verdaderos antecedentes para la investigación del comunismo en relación a los trabajadores. En primer lugar, Mirta Lobato, en La vida en las fábricas. Protesta y política en una comunidad obrera, Berisso (1904-1970), fruto de sus investigaciones de doctorado, examinó el mundo del trabajo femenino haciendo especial énfasis entre fines del siglo XIX y las primeras cuatro décadas del siglo XX. Más adelante nos referiremos en detalle a las implicancias de esta obra, ahora queremos destacar que en el devenir de su investigación sobre las y los trabajadores de Berisso significó avances muy lúcidos sobre la influencia del comunismo en aquella comunidad de trabajadores. El trabajo de Lobato abre una puerta a la investigación sobre la influencia del comunismo en la clase trabajadora al introducir el análisis de las relaciones de género en el movimiento obrero.

En segundo lugar, un trabajo relevante, en lo que respecta a la historia del PC, es el de Hernán Camarero. Los resultados de sus investigaciones de doctorado y maestría se han dado a conocer en A la conquista de la clase obrera. Los comunistas y el mundo del trabajo en la Argentina, 1920-1935. ${ }^{30}$ Asimismo, sus artículos en revistas académicas y ponencias en jornadas han dado cuenta del avance de su trabajo, tanto para el período previo como para los años posteriores a 1935. Las obras de Camarero constituyen las primeras investigaciones académicas que abordan la historia del PC argentino en relación con su inserción en el mundo del trabajo desde sus inicios en los años de 1920.

El libro de Camarero explora las estrategias políticas del PC, su inserción en el mundo del trabajo y el despliegue del partido a nivel barrial, tanto en Capital Federal como del GBA. También aborda la influencia del comunismo en la experiencia obrera, así como en la conformación de una identidad y una cultura proletaria, ${ }^{31}$ y se aproxima a estos tópicos en la ciudad de Córdoba y Santa Fe, progresando en el estudio de la implantación del

\footnotetext{
${ }^{29}$ Camarero, Hernán, A la conquista..., op. cit.; Camarero, Hernán, Comunismo y movimiento obrero en la Argentina 1914-1943, tesis doctoral, Facultad de Filosofía y Letras, Universidad de Buenos Aires, 2008; Lobato, Mirta Z., "Rojos. Algunas reflexiones sobre las relaciones entre los comunistas y el mundo del trabajo en la década del 30", Prismas, $\mathrm{N}^{\circ}$ 6, Buenos Aires, 2002, pp. 5-15; Lobato, Mirta Z., La vida en las fábricas. Trabajo, protesta y política en una comunidad obrera, Berisso (1904-1970), Buenos Aires, Prometeo, 2001; Iñigo Carrera, Nicolás, La estrategia de la ..., op. cit.

${ }^{30}$ Camarero, Hernán, A la conquista..., op. cit.

${ }^{31}$ Camarero, Hernán, A la conquista..., op. cit., pp. 217-284.
} 
comunismo en el interior del país. ${ }^{32}$ Su trabajo, si bien todavía sesgado desde el punto de vista de género, ha abierto diversos caminos de investigación.

Los estudios descriptos tuvieron efecto en la historiografía. Más allá de las particulares líneas que abrieron, muchos estudios actuales tienen su raíz en los trabajos de Lobato y Camarero. A comienzos de la década que estamos transitando, se produjo un próspero desarrollo de indagaciones que abordaron el cruce entre comunismo, sindicalismo y movimiento obrero desde la historia social, los cuales tomaron distancia de las preguntas sobre los orígenes del peronismo, abandonando las tradicionales miradas desde las dirigencias sindicales o partidarias, dando lugar a la experiencia de los trabajadores y al comunismo como parte de la misma y ampliando el trabajo a otras provincias del país. ${ }^{33}$

Dentro de este grupo de trabajos encontramos dos que abordan la industria textil, pero no desde la perspectiva tradicional de la historia de la industria, que se centró en el desarrollo del empresariado y sus derroteros en la relación con el Estado, ${ }^{34}$ sino ampliando la perspectiva a las experiencias de los trabajadores del sector, las condiciones de trabajo, etc. Nos referimos a los trabajos de Diego Ceruso (2010) y Marcos Schiavi (2012). ${ }^{35}$ Por un lado, el examen de Ceruso tomó la fábrica textil como espacio de lucha y de construcción de identidades. Hizo énfasis en la organización sindical, pero desde sus organismos de base: comisiones internas, de lucha de propaganda, etc. Aquí encontramos un estudio más abarcativo sobre la UOT. Por otro lado, el trabajo de Marcos Schiavi estudió la participación de los comunistas en la industria textil durante la emergencia del peronismo, presentando los dilemas que afrontó el PC frente a la constitución de los denominados "sindicatos paralelos".

\footnotetext{
${ }^{32}$ Camarero, Hernán, A la conquista..., op. cit., pp. 65-132.

${ }^{33}$ Santa Cruz, Claudia, "El partido comunista ante el problema del transporte en 1943: posición política, acción gremial y nuevas alianzas en el seno del transporte de autos colectivos", Dossier "Nuevas aproximaciones historiográficas sobre el vínculo del PC y el movimiento obrero, 2012, disponible en http://historiapolitica.com/datos/biblioteca/pcmovo_santacruz.pdf; fecha de consulta: 8 de julio de 2015; Schiavi, Marcos, "La dinámica sindical durante los dos primeros gobiernos peronistas (1946-1955). El caso de las industrias metalúrgica y textil en la ciudad de Buenos Aires y sus alrededores", tesis de doctorado, Universidad de Buenos Aires-Université París 8, 2011; Mastrángelo, Mariana, Rojos en la Córdoba obrera, 1930-1943, Buenos Aires, Imago Mundi, 2011; Ceruso, Diego, Comisiones internas de fábrica. Desde la huelga de la construcción de 1935 hasta el golpe de Estado de 1943, Vicente López PIMSA-Dialektik, 2010; Gurbanov, Andrés y Rodríguez, Sebastián, "La huelga metalúrgica de 1942 y la crisis de la dirigencia comunista en los orígenes del peronismo", Nuevo Topo, revista de historia y pensamiento crítico, № 4, 2007, pp. 61-83.

Belini, Claudio, "El grupo Bunge y la política económica del primer peronismo, 1943-1952", Latin American Research Review, vol. 41, № 1, 2006, California, pp. 27-50; Belini, Claudio, "Monopolios, poder y política. Perón contra el grupo Bemberg, 1948-1959”, Secuencia. Revista de Historia y Ciencias Sociales, $\mathrm{N}^{\circ}$ 70, Buenos Aires, 2008, pp. 103-128; Belini, Claudio, La industria peronista, 1946-1955. Políticas públicas y cambio estructural, Buenos Aires, Edhasa, 2009; Belini, Claudio y Rougier, Marcelo, El Estado empresario en la industria argentina. Conformación y crisis, Buenos Aires, Manantial, 2008; Colman, Oscar, "La industria textil...", op. cit.; Dorfman, Adolfo, Historia de la industria ..., op. cit.

${ }^{35}$ Ceruso, Diego (2010), Comisiones internas de fábrica..., op. cit.; Schiavi, Marcos , La dinámica sindical..., op. cit.
} 


\section{Un estudio generizado de la inserción del comunismo en el movimiento obrero. Antecedentes}

Si bien algunos de los ejercicios historiográficos que hemos referenciado hasta el momento, se constituyen en progresos para el conocimiento del mundo obrero de la industria textil, de su sindicato, sus condiciones de trabajo, de contratación, así como de la historia del PC y cómo fue su inserción en el movimiento obrero en general y en el textil en particular, todavía hay grandes ausencias. Principalmente, no se da cuenta de la especificidad del trabajo industrial femenino, de la incidencia de las normativas de género en el entramado de las condiciones de trabajo, de las particularidades de la militancia de las obreras ni de los esfuerzos del PC por llegar al sector femenino de la clase obrera textil. Como ampliaremos más adelante, si bien se ha avanzado en cuanto a la organización de las mujeres dentro del partido y en agrupaciones de masas, ${ }^{36}$ no se ha desarrollado el estudio en particular de las trabajadoras y la impronta que tuvo el objetivo partidario en la experiencia concreta de las obreras y los obreros textiles.

De hecho, esta temática ha quedado opacada a lo largo de toda la bibliografía que hemos citado en torno al PC y al movimiento obrero. Esto se podría explicar porque todavía hay un sentido común entre los historiadores del movimiento obrero que universaliza al trabajador masculino y masculiniza a la clase obrera, por lo que quedan invisibilizadas tanto las problemáticas específicas de las trabajadoras en calidad de obreras, como lo que tiene que ver con sus reivindicaciones particulares, además de las características específicas de su militancia. Al mismo tiempo, en los análisis mencionados, se obtura el examen de las relaciones de género al utilizar una categoría de clase social también universalizada en términos masculinos. En este apartado, haremos una revisión de la bibliografía que, por un lado, ha incorporado las relaciones de género en los estudios sobre los trabajadores y el movimiento obrero y que, por otro lado, ha analizado la militancia partidaria teniendo en cuenta las relaciones de género. Consideramos que estos aportes contienen claves teóricometodológicas que nos ayudan a avanzar en una perspectiva que involucra las relaciones de género en el examen del movimiento obrero.

La historia de las mujeres ha sido ensombrecida por una mirada centrada en prácticas de varones que fueron presentadas como la totalidad, el universal y la norma del movimiento obrero. ${ }^{37}$ Los estudios de mujeres buscaron revertir esto pero, en la mayoría de los casos, al incorporarlas como un objeto de estudio en sí, cayeron en la sustitución de la mujer por el

\footnotetext{
${ }^{36}$ Valobra, Adriana, "Formación de cuadros y frentes populares: las mujeres en el Partido Comunista de Argentina, 1935-1951", Revista Izquierdas, N 23, Santiago de Chile, 2015, pp. 127-156; Valobra, Adriana, Mujeres en espacios bonaerenses, La Plata, Edulp, 2009.

${ }^{37}$ Rodríguez, Florencia, “¿Masculinidad Clasista? Aportes a un debate abierto en el campo de la historia latinoamericana contemporánea", Fazendo Genero 2010, Diasporas, Diversidades e Deslocamentos, UFSC, Florianópolis, agosto de 2010.
} 
género. ${ }^{38}$ Los estudios de género, en cambio, implican entenderlo como una relación social $^{39}$ al señalar que los roles sexuales se construyen en un contexto social determinado. ${ }^{40}$ No se trata sólo de visibilizar a la mujer en la historia universal masculina sino hacer otro tipo de historia y, en este caso en particular, visibilizar las relaciones de género en el marco de la sociedad contemporánea y el conflicto social que le es propio, marcando la doble opresión y explotación de las trabajadoras.

Esta exclusión se puede observar en la historiografía sobre movimiento obrero y sobre todo en la rama textil en particular, ya que este sector industrial ni siquiera ha recibido la atención debida por los historiadores del movimiento obrero. Débora D’Antonio y Omar Acha, en un estudio sobre los conflictos en la industria textil, afirman que "se operó en general una invisibilización de la participación femenina en la fuerza de trabajo, y aún más respecto de la intervención de ellas en los conflictos sindicales y políticos". ${ }^{41} \mathrm{La}$ escasez de estudios sobre el gremio textil desde una perspectiva que involucre las relaciones de género, ${ }^{42}$ donde la mayoría de la mano de obra fue femenina, es ejemplo de esto, puesto que en la historia tradicional ha prevalecido un sentido común que analizó al textil como un gremio pasivo por la poca participación de las mujeres en la militancia gremial. ${ }^{43}$

Durante las últimas décadas del siglo XX, se comenzaron a revertir estos presupuestos. A nivel internacional, los estudios sobre movimiento obrero se fueron complejizando. En primer lugar, en los años 80 del siglo pasado la New Labor History estadounidense, nutriéndose del marxismo británico, revisó la narrativa de la vieja historia social, ${ }^{44}$ incorporando al análisis las categorías de raza, etnicidad, género y, más recientemente, la sexualidad y la orientación sexual. De esta manera, buscó complejizar los relatos del movimiento obrero para dar cuenta de "identidades" más complejas. Asimismo, los trabajos se fueron ampliando para incluir no sólo al sindicalismo (como las historias tradicionales) sino al conjunto de los trabajadores, al análisis de las fábricas y el lugar de trabajo, el proceso de trabajo ${ }^{45}$ y su configuración sexuada, así como las comunidades y la familia

\footnotetext{
${ }^{38}$ Valobra, Adriana, "Algunas consideraciones acerca de la historia de las mujeres y género en Argentina", Nuevo Topo. Revista de historia y pensamiento crítico, $\mathrm{N}^{\mathrm{o}}$ 1, Buenos Aires., 2005, pp. 77-79.

${ }^{39}$ Pita, Valeria S., "Estudios de género e historia. Situación y perspectivas", Mora, No 4, Buenos Aires, 1998, pp. 72-82.

${ }^{40}$ Scott, Joan W., "El género: una categoría útil para el análisis histórico", en Amelang, J. y Nash, M. (coords.), Historia y género: las mujeres en la Europa moderna y contemporánea, Valencia, Alfons el Magnánim, 1990.

${ }^{41}$ D’Antonio, Débora y Acha, Omar, "La clase obrera «invisible»...”, op. cit., p. 232.

${ }^{42}$ Como excepciones están los trabajos de Lobato y D'Antonio y Acha, ya citados; Ceva, Mariela, Empresas, trabajo e inmigración en la Argentina. Casos de la Fábrica Argentina Alpargatas y Algodonera Flandria (1887-1955), Buenos Aires, Biblos, 2010 y Ceruso, Diego, Comisiones internas de fábrica ..., op. cit.

${ }^{43}$ Di Tella, Torcuato S.,"La Unión Obrera Textil...", op. cit. Ver también, por ejemplo, Bergquist, Carlos, Los trabajadores latinoamericanos. Estudios comparativos de Chile, Argentina, Colombia y Venezuela, Colombia, Siglo XXI, 1988, pp. 158-159.

${ }^{44}$ Weinstein, Barbara, "La investigación sobre identidad cultural y ciudadanía en Estados Unidos: de la nueva historia social a la nueva historia cultural", Fronteras de la historia, vol. 5, Bogotá, 2000, pp. 73-91.

${ }^{45}$ Braverman, Henry, Trabajo y capital monopolista, México, Nuestro Tiempo, 1980.
} 
Verónica Norando, Comunismo, Género y movimiento obrero: un estado de la cuestión, Izquierdas, 30, Octubre 2016:26-64

obrera. ${ }^{46}$ En segundo lugar, las influencias de los estudios de género se hicieron palpables ya en la década del 90 del siglo XX. ${ }^{47}$ Fueron los planteos de Joan Scott -entender al género como una relación social que implica un acceso desigual al poder y los bienes culturales, simbólicos y materiales- ${ }^{48}$ los que más influyeron en la historiografía local y complejizaron la perspectiva sobre la historia social de los trabajadores. ${ }^{49}$

De hecho, se puede afirmar que en los últimos veinticinco años los estudios de género han comenzado a complejizar la historia social en la Argentina. Las influencias de Catherine Hall (2013 [1990]) y Dorothy Thompson (2013 [1993]) se hicieron notar en la producción local. ${ }^{50}$ De esta manera, los avances sobre las experiencias de trabajadores y trabajadoras, el movimiento obrero, la militancia gremial, el activismo político, la relación con el Estado y sus respuestas al conflicto social comenzaron a ser abordados desde una perspectiva que involucra las relaciones de género. ${ }^{51}$ Estos trabajos surgieron al calor del avance de los

${ }^{46}$ Montgomery, David [1988], The fall of the house of labour, Cambridge University Press, 2005; Baron, Aba (ed.), Work Engendered: Toward a New History of American Labor, Ithaca, Cornell University Press, 1991; Kessler-Harris, A. (1982), Out to Work: A History of Wage-Earning Women in the United States, Nueva York, Oxford University Press; Gutman, H. (1976), Work, Culture and Society in Industrializing America: Essays in American Working-Class and Social History, Nueva York, Kunz.

${ }^{47}$ Scott, Joan W., "El género: una...", op. cit.; Scott, Joan W., "Prefacio a Gender and politics of history", Cuadernos Pagu, $\mathrm{N}^{\circ}$ 3, Universidad Estadual de Campinas, 1994, pp. 12-13; Offen, Karen, Escribir la historia de las mujeres: Perspectivas Internacionales, Indiana University Press, 1991; Gadol, Kelly .J., "La relación social entre los sexos: implicaciones metodológicas de la historia de las mujeres", en Navarro, Marisa y Stimpson, Ccatherine, Sexualidad, género y roles sexuales, Buenos Aires, FCE, 1999; Lerner, Gerda, La creación del patriarcado, Barcelona, Crítica, 1990; Zemon Davis, Nathaly, "Las formas de la historia social”, Historia Social, $\mathrm{N}^{\circ}$ 10, Valencia, primavera-verano, 1991, pp. 177-184; Tilly, Louise A., "Género, historia de las mujeres e historia social", Cuadernos Pagu, N³, Universidad Estadual de Campinas, 1994, pp. 29-62.

${ }^{48}$ Scott, Joan W., "El género: una categoría útil...", op. cit.

${ }^{49}$ Scott, Joan W., "La mujer trabajadora en el siglo XIX”, en Duby, G. y Perrot, M., Historia de las mujeres en Occidente, t. 4: El siglo XIX, Madrid, Taurus, 2000.

${ }^{50}$ Hall, Catherine "La historia de Samuel y Jemima: Género y Cultura de la clase trabajadora en la Inglaterra del siglo XIX", en Mora Vol. 19, (2), Buenos Aires, 2013; Thompson, Dorothy "Las mujeres y la radicalidad política en el siglo XIX: una dimensión ignorada”, en Mora, Vol. 19, (2), Buenos Aires, 2013.

51 Barrancos, Dora, Anarquismo, educación y costumbres en la Argentina de principios de siglo, Buenos Aires, Contrapunto, 1990; Barrancos, Dora, Cultura, educación y trabajadores (1890-1930), Buenos Aires, CEAL, 1992; Barrancos, Dora, La escena iluminada. Ciencias para los trabajadores (1890-1930), Buenos Aires, Plus Ultra, 1996; Barrancos, Dora, "Moral sexual, sexualidad y mujeres trabajadoras en el período de entreguerras", en Devoto, Fernando y Madero, M., La Historia de la Vida Privada en la Argentina, Buenos Aires, Taurus, 1999; Lobato, Mirta Z., "Mujeres en la fábrica. El caso de las obreras del frigorífico Armour, 1915-1969", Anuario IEHS , N 5, Buenos Aires, 1990, pp. 35-62; Lobato, Mirta Z., "Mujeres obreras, protesta y acción gremial en la Argentina: los casos de la industria frigorífica y textil en Berisso", en Barrancos, Dora, Historia y Género, Buenos Aires, CEAL, 1993; Lobato, Mirta Z., La vida en las fábricas..., op. cit.; Lobato, Mirta Z., Historia de las.., op. cit.; Lobato, Mirta Z., La prensa obrera, Buenos Aires, Edhasa, 2009; Ceva, Mariela, Empresas trabajo e inmigración en la Argentina..., op. cit.; Rodríguez, Florencia, “¿Masculinidad Clasista? ...”, op. cit.; Andújar, Andrea, "El amor en tiempos de revolución. Batallas, telenovelas, sexo y rock and roll”, en Andújar, A. et al. (comps.), De minifaldas, militancias y revoluciones. Exploraciones sobre los 70 en la Argentina, Buenos Aires, Luxemburg, 2009; Palermo, Silvana, “'Trabajo masculino protesta femenina? La participación de la mujer en la gran huelga ferroviaria de 1917”, 
Verónica Norando, Comunismo, Género y movimiento obrero: un estado de la cuestión, Izquierdas, 30, Octubre 2016:26-64

estudios de género a nivel internacional y han ampliado los análisis sobre los trabajadores describiendo las condiciones de trabajo, las ideas que circularon en la sociedad acerca del trabajo de las mujeres, el accionar gremial de las trabajadoras y la relación con el Estado en lo que se refiere al desarrollo de políticas sociales y leyes protectoras del trabajo y de la maternidad.

Entre estos trabajos destacaremos algunos que brindan claves teórico-interpretativas que proponemos retomar. En primer lugar, vamos a profundizar en el aporte de Mirta Zaida Lobato. ${ }^{52}$ Ya hemos hecho una breve referencia de La vida en las fábricas..., pero aquí nos interesa subrayar su propuesta teórica de análisis histórico. ${ }^{53}$ La autora se sirve de las herramientas conceptuales que nos brinda el marxismo británico, particularmente el trabajo de Edward Palmer Thompson. ${ }^{54}$ Lobato parte de una definición de clase social compleja y dinámica, pero al mismo tiempo concreta y delimitada. Un concepto de clase social donde tiene un papel determinante la experiencia de las personas.

Esta concepción de las clases sociales le permitió incluir las diferentes experiencias de clase determinadas por las diferencias sexuales y de género. En palabras de la autora:

en Bravo, M.C.; Gil Lozano F. y Pita, V. (comps.), Historia de luchas, resistencias y representaciones. Mujeres en la Argentina. Siglos XIX y XX, Tucumán, Universidad de Tucumán, 2007; Pascucci, Silvina, Costureras, monjas y anarquistas. Trabajo femenino, Iglesia y lucha de clases en la industria del vestido (Buenos Aires 1890-1940), Buenos Aires, Razón y Revolución, 2007; Queirolo, Graciela, "Mujeres que trabajan...", op. cit.; Queirolo, Graciela, "El mundo de las empleadas administrativas: perfiles laborales y carreras individuales (Buenos Aires, 1920-1940)", Trabajos y Comunicaciones, № 34, Buenos Aires, 2008, disponible

en http://www.trabajosycomunicaciones.fahce.unlp.edu.ar/article/viewFile/TYC2008n34a07/pdf_116; Queirolo, Graciela, "Las mujeres y los niños ...", op. cit.; Ramacciotti, Karina I., "Una mirada sobre el estudio de la política social en la Argentina", Nuevo Topo. Revista de historia y pensamiento crítico, $\mathrm{N}^{\circ} 1$, Buenos Aires, 2005; Ramacciotti, Karina I., "Las trabajadoras en la mira estatal: Propuestas de reforma de la Caja de Maternidad (1934-1955)", Trabajos y Comunicaciones, $2^{\circ}$ época, UNLP, 2005; Ramacciotti, Karina I., "De la culpa al seguro. La ley de accidentes de trabajo, 1915-1955", Mundos do Trabalho, vol. 3, No 5, ANPUH, 2011, pp. 266-284; Biernat, Carolina y Ramacciotti, Karina I., Crecer y multiplicarse. La política sanitaria materno-infantil argentina 1900-1960, Buenos Aires, Biblos, 2013; Lavrin, Asunción, Mujeres, Feminismo y cambio social en Argentina, Chile y Uruguay 1890-1940, Santiago de Chile, Centro de Investigaciones Diego Barros Aranda, 2005; Nari, Marcela, "El movimiento obrero y el trabajo femenino. Un análisis de los congresos obreros durante el período 1890-1921", en Knecher, L. y Panaia, M. (comps.), La otra mitad del país. La mujer en la sociedad argentina, Buenos Aires, CEAL, 1994; Nari, Marcela, Políticas de maternidad y maternalismo político, Buenos Aires, Biblos, 2004; D’Antonio, Débora, "Representaciones de género en la huelga de la construcción, Buenos Aires, 1935-1936", en Gil Lozano, F.; Pita V. e Ini, G., Historia de las mujeres en la Argentina, Buenos Aires, Taurus, 2000; D'Antonio, Débora y Acha, Omar, "La clase obrera «invisible» ", op. cit.; entre otros.

${ }^{52}$ Lobato, Mirta Z., La vida en las fábricas..., op. cit.

${ }^{53}$ Lobato, Mirta Z., La vida en las fábricas..., op. cit.

${ }^{54}$ Thompson, Edward P. La formación de la clase obrera en Inglaterra, Barcelona, Crítica, 1989. 
La experiencia del trabajo impacta diferencialmente sobre hombres y mujeres, y las relaciones que se establecen en las fábricas generan un proceso conflictivo de acentuación de las asimetrías [de género]. En el proceso de construcción social se conforma un conjunto de creencias, ideologías, valores, actitudes que diferencia a los hombres de las mujeres. Esas diferencias se expresan en las desigualdades de acceso a los bienes económicos y simbólicos por parte de las mujeres. ${ }^{55}$

Este abordaje de las experiencias laborales allana el camino hacia el estudio de la clase obrera desde una perspectiva que no deja de lado las disímiles experiencias de clase marcadas por las diferencias sexuales y de género. En otras palabras, permite sexuar los estudios sobre el movimiento obrero.

En consonancia con los lineamientos teóricos que articulan las investigaciones de Mirta Lobato, el trabajo de Silvana Palermo se centra en las experiencias de lucha de las mujeres de la clase obrera ${ }^{56}$ En ¿Trabajo masculino, protesta femenina? La participación de la mujer en la gran huelga ferroviaria de 1917 se enfoca en el activismo obrero femenino de un sector laboral con mayoría de mano de obra masculina: los ferrocarriles. A través de este estudio de caso, la autora demuestra cómo las madres, esposas, hermanas e hijas de los ferroviarios tuvieron una activa participación en los conflictos del sector. Uno de los elementos más interesantes de este estudio es el análisis sexuado y generizado del activismo obrero para demostrar las particularidades de la militancia femenina. Además, a nivel teórico la autora también retoma los planteos de Temma Kaplan sobre la constitución de una "conciencia femenina",57 y nos permite profundizar sobre los lazos entre ésta y la conciencia de clase y revisar el activismo femenino en los conflictos, inclusive en aquellos sectores que se caracterizaban por el predominio del trabajo masculino. En este sentido, también destacaremos el trabajo de Andrea Andújar, En demanda de lo justo. Conflictos por derechos en la Patagonia petrolera. 1932, donde la autora retoma una serie de temáticas cuya visibilización se convierte en fundamental para estudiar las relaciones de género en una comunidad obrera en relación con el comunismo. En un relato sobre el conflicto petrolero de 1932, Andújar reconstruye las relaciones de género al interior de la clase obrera y presta atención a la relación con el PC. Así, su trabajo nos brinda claves para entender esta relación y cómo las determinaciones de género influyen en el accionar político de mujeres y varones. ${ }^{58}$

\footnotetext{
${ }^{55}$ Lobato, Mirta Z., La vida en las fábricas..., op. cit. p. 32.

${ }^{56}$ Palermo, Silvana, “¿Trabajo masculino, protesta femenina?...”, op. cit.

${ }^{57}$ Kaplan, Temma, "Conciencia femenina y acción colectiva. El caso de Barcelona, 1910-1918", en Amelang, J.S. y Nash, Mary (comps.), Historia y Género. Las mujeres en la Europa Moderna y Contemporánea, Valencia, Alfons El Magnánim, 1990.

${ }^{58}$ Andújar, Andrea, "En demanda de lo justo: conflictos por derechos en la Patagonia petrolera" Comodoro Rivadavia, 1932", Páginas, año 6, N 12, 2014, pp. 41-67.
} 
En otra línea de trabajo, pero compartiendo conceptualizaciones matrices de los estudios de género, Marcela Nari, nos legó una serie de claves interpretativas fundamentales para el estudio de las experiencias obreras: el maternalismo.$^{59}$ En el recorrido de su investigación, la autora va desentrañando la poderosa influencia de la maternalización de las mujeres y sus repercusiones en las políticas de Estado. Nos ha dejado uno de los abordajes más completos del ideograma maternalista desde fines del siglo XIX hasta la emergencia del peronismo. En la misma línea de trabajo se encuentra el libro de Karina Ramacciotti y Carolina Biernat, Crecer y multiplicarse. La política sanitaria materno-infantil. Argentina, 1900-1960. Las autoras nos brindan una serie de claves interpretativas desde la historia social y los estudios de género para la comprensión de la génesis y la historia de las políticas sociales en la Argentina. Poniendo el foco en las políticas de Estado con relación a las mujeres, este libro permite dilucidar las políticas sociales que se diseñaron e implementaron teniendo en cuenta las demandas que se planteaban, desde el ámbito médico, a la salud de las mujeres en tanto su capacidad reproductiva. ${ }^{60} \mathrm{Si}$ bien la mirada se posiciona desde el discurso médico, nos interesa pues en varios aspectos se asemeja a las denuncias realizadas desde la prensa gremial de los trabajadores.

También tenemos que destacar una serie de estudios que se dedicaron a la participación femenina en el ámbito político. Es indiscutible la importancia del trabajo de Dora Barrancos sobre las socialistas y sus luchas para impulsar la igualación civil, social y política de las mujeres. ${ }^{61}$ También hay aproximaciones que han visibilizado la participación de las mujeres en movimientos sociales y partidos políticos. ${ }^{62}$ Estos estudios han abordado la participación femenina en el movimiento anarquista, el Partido Comunista, Socialista, el Partido Peronista Femenino y la Unión Cívica Radical, contribuyendo, de manera colateral, al conocimiento sobre las demandas sociales y económicas de las trabajadoras y la relación de estas obreras con los partidos políticos.

Teniendo como centro las organizaciones políticas ligadas al PC y al propio partido, también se han llevado adelante estudios que desde una perspectiva de género se ocuparon de agrupaciones de mujeres exclusivamente, como la Unión Argentina de Mujeres (UAM), en los cuales se posó la mirada sobre las intelectuales liberales que la integraban y también

\footnotetext{
${ }^{59}$ Nari, Marcela, Políticas de maternidad..., op. cit.

${ }^{60}$ Ramacciotti, Karina I. y Biernat, Carolina, Crecer y multiplicarse ..., op. cit.

${ }^{61}$ Barrancos, Dora, "La conquista del sufragio femenino en el Río de la Plata", en Barrancos, D. y Cano, G., Historia de las mujeres en España y América Latina, t. III, Madrid, Cátedra, 2006.

${ }^{62}$ Valobra, Adriana, Del hogar a las urnas. Recorridos de la ciudadanía política femenina. Argentina 19461955, Buenos Aires, Prohistoria, 2010; Valobra, Adriana, "Formación de cuadros...", op. cit.; Barry, Carolina, Evita capitana. El partido peronista femenino 1949-1955, Buenos Aires, UNTREF, 2009; Giordano, Verónica, "Los derechos civiles de las mujeres y la reforma del Código Civil de 1936: el acontecimiento, la coyuntura, la estructura", Terceras Jornadas de Jóvenes Investigadores del Instituto de Investigaciones Gino Germani, UBA, 2005; Barrancos, Dora, Inclusión/Exclusión. Historia con mujeres, Buenos Aires, FCE, 2002; Navarro, Marisa, Evita, Buenos Aires, Planeta; Bianchi, S. y Sanchís, N. (1988), El Partido Peronista Femenino, Buenos Aires, CEAL, 1994.
} 
sobre distintos aspectos por los que se movilizaron estas mujeres. ${ }^{63}$ Otros estudios se concentraron en la Junta de la Victoria $(\mathrm{JV}) .{ }^{64} \mathrm{Y}$, más recientemente, otros se enfocan en la discursividad de algunas dirigentes comunistas destacadas. ${ }^{65}$ Los estudios más relevantes sobre el tema son los de Adriana María Valobra, que viene incursionando desde distintos ángulos en la organización de las mujeres por el PC desde una perspectiva que involucra las relaciones de género. La autora ha estudiado a las comunistas de la Unión de Mujeres Argentinas (UMA) y la Unión Argentina de Mujeres (UAM) haciendo énfasis en la organización femenina del PC entre 1946 y $1955 .{ }^{66}$ Valobra plantea que el PC tuvo una doble estrategia de organización de las mujeres: una extrapartidaria y una partidaria. ${ }^{67}$

Este desarrollo tiene perspectivas muy ricas ya que el $\mathrm{PC}$, tanto antes como durante el peronismo, ha dedicado mucha energía a la organización de las mujeres y en particular de las trabajadoras. Pero, como bien plantea Valobra, también ha consagrado una gran cantidad de esfuerzos a la organización de las mujeres, en tanto tales (sin importar que fueran proletarias o burguesas), en organizaciones antiimperialistas y antifascistas bajo la estrategia de frentes populares. ${ }^{68} \mathrm{Si}$ bien esta última investigación no enfocó a las trabajadoras de los gremios con mayor influencia comunista en particular, sino a las mujeres en sí mismas, allana el camino para adentrarse en el examen de la organización de las obreras por parte del PC. Con los trabajos de Adriana Valobra terminamos de recorrer el camino de las investigaciones que se convierten en aportes fundamentales para una historia generizada de la relación del comunismo con el movimiento obrero. En lo que sigue, avanzaremos en una propuesta metodológica, retomando algunas de las perspectivas que hemos destacado hasta aquí.

${ }^{63}$ Giordano, Verónica, Ciudadanas incapaces. La construcción de los derechos civiles de las mujeres en Argentina, Brasil, Chile y Uruguay en el siglo XX, Buenos Aires, Teseo, 2012; Cosse, Isabela, "La lucha por los derechos femeninos: Victoria Ocampo y la Unión Argentina de Mujeres (1936)", Revista Humanitas, año XXVI, N 34, Universidad Nacional de Tucumán, 2008, pp. 136-156; Queirolo, Graciela, "La mujer en la sociedad moderna a través de los escritos de Victoria Ocampo (1935-1953)", en Alicia Salomone et al. (eds.), Modernidad en otro tono. Escritura de mujeres latinoamericanas: 1920-1950, Santiago de Chile, Cuarto Propio, 2004.

${ }^{64}$ McGee Deutsch, Sandra, “Argentine Women Against Fascism: The Junta de la Victoria, 1941-1947”, Politics, Religion and Ideology, vol. 13, N², 2012, pp. 221-236; McGee Deutsch, Sandra, "Mujeres, antifascismo y democracia: la Junta de la Victoria, 1941-1947”, Anuario IEHS, $\mathrm{N}^{\circ}$ 28, Buenos Aires, 2013, pp. 157-175.

${ }^{65}$ Valobra, Adriana, "Formación de cuadros...", op. cit.; Perrig, Sara, "Alcira de la Peña, los derechos políticos femeninos y las elecciones de 1951", Serie Cuadernos del IDES, № 27, Buenos Aires, Instituto de Desarrollo Económico y Social, 2013, pp. 3-20.

${ }^{66}$ Valobra, Adriana, Del hogar a las urnas... op. cit.; Valobra, Adriana, "La UMA en marcha. El Partido Comunista Argentino y las tradiciones y estrategias de movilización social en el primer gobierno peronista: el caso de la Unión de Mujeres Argentinas (UMA)", Canadian Journal of Latin American and Caribbean Studies, vol. 30, N 60, Montreal, Universitè de Québec, 2005, pp. 155-183; Valobra, Adriana, "Partidos, tradiciones y estrategias de movilización social: de la Junta de la Victoria a la Unión de Mujeres de la Argentina", Prohistoria, año IX, Nº 9, Rosario, 2005, pp. 67-82.

${ }^{67}$ Valobra, Adriana, Del hogar a las urnas..., op. cit.; Valobra, A. (2015), "Formación de cuadros...", op. cit.

${ }^{68}$ Valobra, Adriana, "Formación de cuadros...", op. cit. 


\section{Las relaciones de género en la clase obrera. Un aporte teórico- metodológico a los estudios sobre comunismo y movimiento obrero}

Consideramos que el modo de producción capitalista rige la sociedad contemporánea y que, al mismo tiempo, ella está estructurada en clases sociales. Asimismo, entendemos que la subordinación de las mujeres a la hegemonía patriarcal es uno de los aspectos que caracterizan a los procesos modernizadores que envuelven a la Argentina a lo largo de los siglos XIX y XX. ${ }^{69}$ Teniendo presentes estas primeras premisas, queremos proponer un análisis marxista de la dimensión de sexo-género en el movimiento obrero. En este sentido, acordamos con Zillah Eisenstein en que la importancia de este análisis para el estudio de la opresión de la mujer es doble, primero proporciona el análisis de clase necesario para el estudio del poder y, segundo, proporciona un método de análisis histórico y dialéctico. ${ }^{70}$ Aunque la dialéctica (como método) es utilizada con mayor frecuencia en los análisis marxistas para estudiar las clases y los conflictos de clase sin incorporar la perspectiva de género, la autora plantea que es válido examinar desde este prisma las relaciones patriarcales que determinan la existencia de las mujeres en el capitalismo. Es factible hacer esto porque "el análisis marxista proporciona las herramientas para comprender todas las relaciones de poder; no hay nada en el método dialéctico e histórico que lo limite sólo a la comprensión de las relaciones de clase" ${ }^{71}$ en el sentido economicista.

Examinando la problemática desde esta perspectiva, consideramos que la sociedad capitalista se organiza a partir de un modo de producción determinado, es decir, en palabras de Karl Marx:

El modo de producción de la vida material, que se constituye por las relaciones, necesarias e independientes de su voluntad en las que los hombres entran. Estas relaciones de producción corresponden a un grado determinado de desarrollo de sus fuerzas productivas materiales. El conjunto de estas relaciones de producción constituye la estructura económica de la sociedad. Este modo de producción de la vida material condiciona el proceso de vida social, política e intelectual en general. ${ }^{72}$

\footnotetext{
${ }^{69}$ Queirolo, Graciela, “Dora Barrancos, Inclusión/Exclusión. Historia con mujeres, Buenos Aires, FCE, 2002, 159 p.”, Nuevo Mundo Mundos Nuevos, 2005, disponible en https://nuevomundo.revues.org/338 ; fecha de consulta: 5 de febrero de 2016.

${ }^{70}$ Eisenstein, Zilah, Patriarcado capitalista y feminismo socialista, México, Siglo XXI, 1980.

${ }^{71}$ Eisenstein, Zilah, Patriarcado capitalista..., op. cit., p. 17.

${ }^{72}$ Marx, Karl, "Prólogo a la contribución a la crítica de la economía política”, Buenos Aires, Comunicaciones, 1980 , p. 37.
} 
El modo de producción capitalista se caracteriza por la producción de mercancías y las relaciones sociales en que entran los hombres y mujeres de manera involuntaria son las relaciones asalariadas. Pero si incorporamos la dimensión de sexo-género en el análisis de este modo de producción, hay que complejizar estas definiciones e incluir las relaciones materiales del patriarcado en las que los hombres y las mujeres entran también de manera involuntaria y que influyen y condicionan directamente la manera de producir, es decir, el modo de producción de la sociedad capitalista. Así, los hombres y las mujeres entran en las relaciones sociales de producción determinados por su condición sexual y las normativas de género, y se relacionan en tanto tales, como hombres y como mujeres. En términos de Heidi Hartmann, partimos de un análisis que combina el patriarcado con el capitalismo. ${ }^{73}$ La división del trabajo en las sociedades occidentales contemporáneas "es resultado de un largo proceso de interacción entre patriarcado y capitalismo". ${ }^{74}$ Siguiendo a la misma autora, sostenemos que, si bien el análisis marxista aporta una visión esencial de las leyes del desarrollo histórico, y de las del capital en particular, "las categorías del marxismo son ciegas al sexo". ${ }^{75}$ Y coincidimos con Hartmann en lo siguiente:

Sólo un análisis específicamente feminista revela el carácter sistemático de las relaciones entre hombre y mujer. Sin embargo, el análisis feminista por sí solo es insuficiente, ya que es ciego a la historia y no es lo bastante materialista. Hay que recurrir tanto al análisis marxista, y en particular a su método histórico y materialista como al feminista, y en especial a la identificación del patriarcado como estructura social e histórica, si se quiere entender el desarrollo de las sociedades capitalistas occidentales. $^{76}$

Si partimos desde un análisis dialéctico, entonces debemos considerar, junto con Shulamith Firestone, que el patriarcado impone relaciones materiales cuya base es el trabajo doméstico, las tareas del cuidado y la reproducción. En palabras de la autora: "La dialéctica del sexo es la dialéctica histórica fundamental y la base material del patriarcado es el trabajo que hacen las mujeres al reproducir la especie". ${ }^{77} \mathrm{Si}$ consideramos, con la autora, las relaciones materiales que impone el patriarcado en conjunto con las relaciones de producción, para caracterizar la sociedad tendríamos que relacionar patriarcado con modo de producción capitalista.

\footnotetext{
${ }^{73}$ Hartmann, Heidi, "Un matrimonio mal avenido: hacia una unión más progresiva entre marxismo y feminismo", Zona Abierta, $\mathrm{N}^{\circ}$ 24, 1980, pp. 80-105.

${ }^{74}$ Hartmann, Heidi, "Capitalismo, patriarcado y segregación de los empleos por sexos", en Borderías, Cristina; Carrasco, Cristina y Alemany, Carmen (comps.), Las mujeres y el trabajo. Rupturas conceptuales, Barcelona, Icaria-FUHEM, 1994, p. 269.

${ }^{75}$ Hartmann, Heidi, "Un matrimonio mal avenido...", op. cit., p. 2.

${ }^{76}$ Ibidem.

${ }^{77}$ Firestone, Shulamit, La dialéctica del sexo, Barcelona, Kairós, 1976, p. 201.
} 
Los planteos de Gerda Lerner sobre el patriarcado lo han contextualizado como un sistema de explotación, a nivel objetivo, lo que impone la división sexual del trabajo (trabajo doméstico-trabajo asalariado) y de opresión a nivel subjetivo, demarcando unas normativas de género jerarquizadas, que se inmiscuyen en todas las relaciones sociales y en la producción de mercancías en particular. Al mismo tiempo, es un sistema histórico, lo que significa que tuvo un comienzo, un origen y puede tener un fin con el devenir del tiempo. ${ }^{78}$ Es una organización que oprime y explota a toda la sociedad en general, y a las mujeres en particular, ya que las mujeres tienen un salario inferior al de los hombres en el capitalismo. Esto se debe a la injerencia de las relaciones patriarcales en la producción y afecta tanto al trabajo individual como al trabajo humano social abstracto. Lerner plantea que el patriarcado es un sistema heredado pero al mismo tiempo fue transformado por el capitalismo pues este sistema es histórico y dinámico. ${ }^{79}$

Si bien no estamos de acuerdo con todos los planteos de Engels sobre los orígenes del patriarcado, sí acordamos en que el capitalismo ha transformado de manera rotunda la opresión y la explotación de la mujer, es decir el patriarcado:

En el antiguo hogar comunista, que comprendía numerosas familias conyugales con sus hijos, la dirección del hogar confiada a las mujeres era también una industria socialmente tan necesaria como el cuidado de proporcionar los víveres, cuidado que se confió a los hombres las cosas cambiaron con la familia patriarcal y aun mas con la familia individual monogámica (capitalista), el gobierno del hogar perdió su carácter social. La sociedad ya no tuvo más que ver con ello. El gobierno del hogar se transformó en un servicio privado; la mujer se transformó en la criada principal sin tomar parte en la producción social. ${ }^{80}$

Y cabe mencionar que otro cambio que ha introducido el capitalismo es que "le ha abierto el camino de la producción social al menos a la mujer proletaria". ${ }^{81}$ En una lectura superficial esta última frase ha sido frecuentemente interpretada por la tradición marxista de una manera un tanto mecánica: la proletarización de la mujer sentaría las bases materiales para una igualdad entre hombres y mujeres; por lo menos en el interior del proletariado. Sin embargo, Engels ajusta esta afirmación cuando habla de "servidumbre doméstica":

\footnotetext{
${ }^{78}$ Lerner, Gerda, La creación del..., op. cit.

${ }^{79}$ Lerner, Gerda, La creación del..., op. cit., p. 23.

${ }^{80}$ Engels, Frederich, El origen de la familia, la propiedad privada y el Estado, Buenos Aires, Acercándonos, 2006, p. 94.

${ }^{81}$ Idem.
} 
La familia individual moderna se funda en la esclavitud doméstica franca o más o menos disimulada de la mujer y la sociedad moderna es una masa cuyas moléculas son las familias individuales. ${ }^{82}$

Otra cuestión a tener en cuenta -que Engels no analiza y también es un cambio producido por el capitalismo respecto del patriarcado ya existente- es la forma en que se desarrolla la proletarización femenina. Si bien ellas trabajan en la producción social, en cambio "no se proletarizan del mismo modo que los hombres"; $; 3$ constituyen una mano de obra subcualificada, su salario es considerado como salario de apoyo, están sometidas más que los hombres a los avatares del desempleo y se encuentran insertas masivamente en los empleos llamados "femeninos". Esto nos demuestra que las mujeres están proletarizadas como tales. Algunos marxistas observaron esto y afirmaron que ellas trabajaban en oficios sistemáticamente subcualificados. Pero veían en ello un vestigio de la desigualdad heredada de las sociedades precapitalistas más que un producto directo de la situación en la que la sociedad burguesa pone a la mujer. Ahora bien, se puede constatar que esta situación lleva mucho más de un siglo y que se reproduce sistemáticamente. No puede ser explicada por la simple subsistencia de desigualdades anteriores al capitalismo; sus raíces están en el funcionamiento propio del sistema que proletariza a la mujer como un grupo diferenciado en relación con los varones.

Según plantea Antoine Artous, si bien Engels observa perfectamente que la proletarización de la mujer viene determinada por el puesto que ocupa en la familia, lo concibe solo en el sentido de que esta proletarización se realiza "en condiciones tales que la mujer, si cumple con sus deberes en el servicio privado de la familia, queda excluida de la producción social y no puede ganar nada; $y$, por otra parte si quiere participar de la industria pública y ganar algo por su propia cuenta, le es imposible cumplir con sus deberes familiares". ${ }^{84}$ Pero el autor nos llama la atención, y estamos de acuerdo con él, en que ésta no es más que una cara del problema. Cuando la mujer se proletariza lo determinante no es que tenga que elegir entre estar al servicio privado de la familia o buscar un trabajo que la haga participar en la producción social, lo determinante es que la obrera es a la vez proletaria y mujer, es decir, no solamente trabaja en la fábrica y en el hogar, sino que la forma en la que participa en la producción se ve predeterminada por su sexo, por un lado y, por el otro, por los roles de género que le impone el patriarcado capitalista. ${ }^{85} \mathrm{~A}$ este respecto, es oportuno citar una frase de Flora Tristán, "La mujer es la proletaria del proletario", ${ }^{86}$ quien fue pionera en

\footnotetext{
${ }^{82}$ Idem.

${ }^{83}$ Artous, Antoine, Los orígenes de la opresión de la mujer, Barcelona, Fontamara, 1982.

${ }^{84}$ Idem.

${ }^{85}$ Idem.

${ }^{86}$ Citado en Guerra, Luciana A., El feminismo socialista de Flora Tristán: Una aproximación a la sabiduría de una paria, trabajo final de grado, Universidad Nacional de La Plata, Facultad de Humanidades y Ciencias de la Educación, 2015, disponible en http://www.memoria.fahce.unlp.edu.ar/tesis/te.1109/te.1109.pdf; fecha de consulta: 3 de enero de 2015.
} 
identificar los puntos comunes entre varones obreros y varones capitalistas respecto a sus privilegios patriarcales.

Como plantea Carole Pateman, el capitalismo escinde el ámbito privado del público para delimitar genéricamente la ubicuidad de las mujeres en ambos universos. ${ }^{87} \mathrm{Y}$, con ello, la generalización de una determinada normativa de género para la mujer determinada por el patriarcado en el capitalismo: el de "especialista" en las tareas domésticas o trabajos de cuidado. ${ }^{88}$ Pero, al mismo tiempo, "el desarrollo del capitalismo, al permitir la participación de la mujer en la producción social, y dadas las contradicciones que afectan a la familia, sienta las bases para que la emancipación de la mujer se convierta en una posibilidad histórica concreta". ${ }^{89}$ Se trata de un proceso contradictorio: el capitalismo significa, a la vez, la generalización del aislamiento de la mujer y, a causa de su proletarización, la multiplicación de las contradicciones sociales que hacen posible la abolición de su opresión.

El proceso de reclusión y aislamiento en las tareas domésticas del hogar y la especialización de las mujeres en este trabajo tiene como corolario no sólo forzosamente su exclusión total de la producción sino la desvalorización absoluta del trabajo que ellas efectúan, ${ }^{90}$ lo que determinará a partir de entonces que el estatuto de la mujer es el lugar que ocupa en el trabajo doméstico. Aquí, siguiendo a Helena Hirata, podemos decir que este lugar de la mujer en las tareas reproductivas es lo que determina las diferencias salariales con los varones, en parte debido a la menor cualificación y, también, al reparto desigual entre los cargos y las ramas económicas. "Así pues, la división del trabajo por género sigue siendo una de las principales causas de las desigualdades salariales y de nivel. Estas desigualdades se ven agravadas por el hecho de valorar más el trabajo masculino que el trabajo de las mujeres y que las «cualidades» femeninas". ${ }^{11}$ Asimismo, Joan Scott también ha planteado, y esta es una de las bases teóricas del análisis que proponemos, las consecuencias de la especialización de la mujer en el trabajo doméstico en su incorporación en el mercado laboral: "De esto se seguía su concentración en ciertos empleos mal pagados, no cualificados, que constituían el reflejo de la prioridad de su misión maternal y de su misión doméstica respecto de cualquier identificación profesional a largo plazo". ${ }^{92}$ Teniendo en cuenta esta relación entre trabajo doméstico y actividad asalariada también retomamos los planteos de Marie-Agnès Barrère-Maurisson, en el sentido de reunificar al sujeto y no considerarlo como escindido en dos partes: la familia y el trabajo. Como esta

\footnotetext{
${ }^{87}$ Pateman, Carol, El Contrato Sexual, México, Anthropos, 1995.

${ }^{88}$ Esquivel, Valeria , "La economía del cuidado en América Latina. Poniendo a los cuidados en el centro de la agenda", Cuadernos atando cabos; deshaciendo nudos, Programa de las Naciones Unidas para el Desarrollo, Centro Regional de América Latina y el Caribe, 2011; Rodríguez Enríquez, Corina, "La economía del cuidado: un aporte para el estudio de políticas públicas", Documento de Trabajo, Buenos Aires, Centro Interdisciplinario para el Estudio de Políticas Públicas, 2005, pp. 1-19.

${ }^{89}$ Artous, Antoine, Los orígenes..., op. cit., p. 15.

${ }^{90}$ Rodríguez Enríquez, Corina, "La economía del cuidado...", op. cit.

${ }^{91}$ Hirata, Helena, "Perspectiva internacional sobre...", op. cit.

${ }^{92}$ Scott, Joan W., "La mujer trabajadora en el...", op. cit.
} 
autora, nosotros consideramos que la experiencia doméstica no está escindida de la experiencia del trabajo asalariado. Éstas son dos facetas de una misma experiencia, en palabras de la autora es la experiencia de la "vida doble" es la "vida en dos partes". 93

Siguiendo el planteo de Artous, la nueva familia que aparece con el advenimiento del capitalismo tiene sus raíces en esta nueva división del trabajo, que constituye su base económica. Pero ésta no es la única determinación que pesa en su origen: hemos de considerar también la responsabilidad que corresponde al Estado moderno burgués, que se va construyendo gradualmente.

Según el autor, el desarrollo y la consolidación del Estado moderno como cuerpo separado de la sociedad civil, la aparición del aspecto político como algo cada vez más separado del conjunto del cuerpo social, la separación entre las relaciones de parentesco y las relaciones políticas, coincide estrechamente con la progresiva autonomía que adquiere la esfera de la producción en relación con el resto de la vida social. La aparición de la familia como lugar separado de la producción social, como lugar donde se realiza el trabajo doméstico, coincide con la aparición de esta nueva familia como institución que implica la separación entre la vida privada y vida pública, tan característica de las modernas sociedades burguesas.

Marx explica que en la sociedad burguesa el hombre vive en dos mundos, totalmente separados el uno del otro: el de la producción y el de la política (aquí, como ciudadano supuestamente igual a los demás ciudadanos). Siguiendo el planteo de Artous, cabría decir que vive en tres mundos; añadiendo, a la separación que se registra entre productor y ciudadano, el corte entre lo privado y lo público, es decir, la división entre actividad profesional, actividad ciudadana y su vida como individuo privado. Esta división del individuo en tres facetas asienta sus raíces en la realidad material del sistema capitalista: la separación, en la propia realidad social, entre la esfera de las relaciones de producción, la de las relaciones políticas, y la de las relaciones de parentesco. Y la familia es la realidad institucional y material que produce el corte entre vida privada y vida pública. La familia es la institución reguladora de las relaciones entre lo privado y lo público, constitutivas del sistema capitalista. De este modo, como venimos explicando, se generaliza la separación entre las dos esferas de la producción -producción privada para el uso doméstico y producción social-, cristalizando en la aparición de una nueva institución, la familia capitalista. Entonces, el destino de la mujer será no solamente especializarse en la producción doméstica sino hacerlo en el interior de tal familia, lugar donde se desarrolla la vida privada que poco a poco se desgaja también de la vida pública.

Partiendo de que la sociedad argentina en que estaban inmersas las obreras estaba dividida en clases, vamos a dar un "definición" somera de lo que consideramos que es una clase social. Y plantearemos, al menos, algunos de los elementos de la definición más relevantes para transmitir lo que entendemos es el conglomerado humano del que forman parte los y

\footnotetext{
${ }^{93}$ Barrère-Maurisson, Marie, La división familiar del trabajo. La vida doble, Buenos Aires, Humánitas, 1999.
} 
las obreras como para establecer un punto de partida teórico-metodológico para el análisis del movimiento obrero argentino.

Podemos comenzar diciendo que una clase social está constituida por un grupo de personas que se relacionan del mismo modo con las fuerzas productivas. Pero no nos quedaremos aquí. Sin estar de acuerdo con la totalidad del planteo de Edward Palmer Thompson, sobre todo con lo esbozado en sus últimas obras -donde el autor da una relevancia definitoria al aspecto "para sí" de la clase, ${ }^{94}$ por lo tanto, lo que definiría a la clase, en última instancia, sería la conciencia-, ${ }^{95}$ sin embargo algunos de sus postulados nos parecen adecuados. Sobre todo rescatamos, siguiendo a Mirta Lobato, ${ }^{96}$ su definición del concepto de clase. Él concibe la clase social como una relación, en la confrontación de grupos sociales y le da importancia fundamental a la experiencia. En sus palabras: "la clase cobra existencia cuando algunos hombres de resultas de sus experiencias comunes (heredadas o compartidas) sienten y articulan la identidad de sus intereses a la vez comunes a ellos mismos y frente a otros hombres cuyos intereses son distintos (y habitualmente opuestos a) los suyos"97 y "la experiencia de clase está ampliamente determinada por las relaciones de producción en las que los hombres nacen, o en las que entran de manera involuntaria".98

Experiencia es un concepto complejo; trataremos de explicitar por qué nos parece útil a la hora del análisis histórico. Tal como fue formulada por Thompson en sus primeras obras, la experiencia de los sujetos está constituida por la materialidad de los sucesos que vivencian y por el pensamiento sobre esos sucesos que, relacionados dialécticamente, dan lugar a la acción (experiencia transformada). La vivencia de los "acontecimientos dan continuamente lugar a experiencia, categoría que incluye la respuesta mental ya sea de un individuo o de un grupo social, a una pluralidad de acontecimientos relacionados entre sí o a muchas repeticiones del mismo acontecimiento". 99 Es claro que este concepto incluye tanto lo objetivo como lo subjetivo, por esto nos parece completo $\mathrm{y}$, al mismo tiempo preciso al incluir una conexión dialéctica entre los dos planos. Esta "experiencia surge espontáneamente del ser social [realidad concreta] y surge con pensamiento. El ser social determina la conciencia social, [...] ¿y cómo ocurre? Dentro del ser social tienen lugar

\footnotetext{
94 Por ejemplo, ver Thompson, Edward P., "Algunas observaciones sobre clase y «falsa conciencia»", Cuadernos de teoría e historia de la historiografía, № 1, 1987, pp. 27-32, donde el autor afirma que "Una clase no puede existir sin una especie cualquiera de conciencia de sí".

${ }^{95}$ Una crítica extensa y profunda en este sentido fue realizada en Anderson, Perry, Teoría, política e historia. Un debate con E.P. Thompson, Madrid, Siglo XXI, 1985. También se puede ver una descripción y balance de este debate en Sazbón, José, "Dos caras del marxismo inglés. El intercambio Thompson-Anderson", Punto de Vista. Revista de cultura, año X, No 29, Buenos Aires, abril de 1987, pp. 11-25.

${ }^{96}$ Lobato, Mirta Z., La vida en las fábricas..., op. cit.

${ }^{97}$ Thompson, Edward P., La formación de la..., op. cit.

98 Thompson, Edward P., La formación..., op. cit, p. 14. Nuestra lectura de Thompson rescata esta definición parcial de lo que sería una clase, ya que en ésta se hace referencia a los factores objetivos y subjetivos, con la relación dialéctica entre ambas dimensiones, con la que acordamos.

99 Thompson, Edward P., Miseria de la teoría, Barcelona, Crítica, 1981, p. 19.
} 
cambios que dan lugar a experiencia transformada: y esta experiencia es determinante, en el sentido en que ejerce presiones sobre la conciencia social existente". ${ }^{100}$

Esta experiencia es, en general, la experiencia del antagonismo social vivida por los sujetos unidos por un interés común (en el caso del proletariado, ser asalariados) o contra otros sujetos unidos por un interés común antagónico (en el caso de la burguesía, ser los dueños de los medios de producción): "El sostenimiento del salario, este interés común que tienen contra su patrono (los asalariados), los reúne en un mismo pensamiento de resistencia: coalición. [...] En esta lucha, se reúnen y se desarrollan los elementos necesarios para una batalla". ${ }^{101}$ Es una experiencia de lucha (sea cual fuere su forma: lucha abierta, en forma de huelgas, insurrecciones, rebeliones, revoluciones, o en el nivel de la lucha cotidiana, en forma de resistencia al trabajo, trabajo a desgano, etc.), de costumbres compartidas y, también, es una experiencia política. La lucha demanda la unión discrecional de los individuos, a fin de lograr el control de las condiciones sociales determinantes de sus posibilidades de desarrollo. Es esta intención explícita de la acción en el campo de las relaciones de poder la que define la lucha de clases como acción esencialmente política. La realidad de ser asalariado constituye el interés común de los trabajadores, establece la base eventual de su antagonismo con los patrones y es el punto de partida estructural para el posible surgimiento de una común acción de resistencia-coalición. Resumiendo, entonces, esta breve caracterización de la clase, se puede decir que "debe entenderse como una categoría histórica, en la que la estructura, la experiencia, la conciencia e identidad operan como elementos constituyentes". ${ }^{102}$

Esta perspectiva nos permite adentrarnos en las experiencias de clase particulares de las obreras como tales, que, en principio, está determinada por el hecho de ser asalariadas y también las principales responsables del trabajo doméstico, el trabajo del cuidado. Este prisma nos permite analizar la complejidad de sus experiencias políticas y sociales.

Teniendo en cuenta nuestra definición del concepto clase social, patriarcado y modo de producción, y por la importancia que le damos a la categoría analítica de experiencia, debemos ahora considerar el lugar particular que ocupan los hombres y las mujeres dentro del conglomerado sexuado que integra la clase según los distintos abordajes sobre movimiento obrero. Siguiendo a Joan Kelly Gadol, aquí introducimos el sexo como categoría socio-histórica. El sexo como categoría nos permite estudiar las diferencias sexuales objetivas a partir de las cuales se producen las construcciones sociales subjetivas de los sistemas de género, ya que el género es una construcción social que genera relaciones asimétricas de poder y, junto con la división sexual del trabajo, son la base del

\footnotetext{
${ }^{100}$ Thompson, Edward P., Miseria de la ..., op. cit., pp. 19-20.

${ }^{101}$ Marx, Karl, Miseria de la filosofía, Buenos Aires, América, 1969, p. 134.

${ }^{102}$ Camarero, Hernán, "Consideraciones sobre la historia social de la Argentina urbana en las décadas de 1920 y 1930: clase obrera y sectores populares", Nuevo Topo. Revista de historia y pensamiento crítico, $\mathrm{N}^{\circ} 4$, 2007, pp. 35-60, Buenos Aires. Para un análisis profundo empírico y analítico de esta cuestión ver Camarero, Hernán, A la conquista de la..., op. cit.
} 
patriarcado. ${ }^{103}$ El género, como concepto, nos ayuda a identificar la explotación particular de las mujeres en el modo de producción capitalista. El lugar sexual que ocupan los integrantes de la clase, su lugar genérico creado a partir de diferencias sexuales, genera diferencias en sus experiencias. Las mujeres de la clase obrera viven una experiencia de clase particular, ya que "ser mujer ha implicado tener un tipo particular de experiencia social, y por ende, histórica". ${ }^{104}$ La mujer es oprimida en tanto mujer y explotada en tanto mujer obrera, y a partir de estos dos elementos materiales constitutivos de las relaciones sociales se construyen las representaciones objetivadas en los discursos, las experiencias y las vivencias que se deben analizar en un examen del movimiento obrero. Los discursos y las representaciones no flotan en el aire sino que son tales al ser producto de la dialéctica de la experiencia tanto de clase como de la vivencia de los roles sexuales dentro de un sistema de sexo-género determinado.

La metodología que propinemos parte de la tradición del feminismo socialista pero se diferencia en algunos aspectos. Buscamos incorporar la dimensión de sexo-género a los análisis en términos de clase. Más allá de las diferencias que nos alejan del construccionismo extremo de Joan Scott, consideramos, con la autora, que el género es una construcción socio-cultural basada en diferencias sexuales objetivas, pero que su análisis no debe basarse sólo en éstas, sino que hay que incluir la relación de estos sujetos sexuados con los medios de producción. Y, en términos más generales, relacionamos el capitalismo con el patriarcado, pero a diferencia de los diversos trabajos que han examinado esta relación (como, por ejemplo, ha planteado el feminismo socialista) no acordamos con el planteo dual de sistemas separados el uno del otro y tampoco nos acercamos a los planteos que postulan dos modos de producción diferenciados ("modo de producción familiar" y "modo de producción industrial"), donde una clase social de mujeres estaría en lucha con una clase social constituida por hombres. ${ }^{105}$ Para nosotros, tanto la explotación del capital como la opresión del patriarcado forman parte de un mismo sistema socio-económico que es, invirtiendo los términos de Zillah Eisenstein, el capitalismo patriarcal. A nuestro entender, la sociedad capitalista es patriarcal, por eso incluimos al patriarcado en el concepto con el cual denominamos a la sociedad, ya que no se trata de idear otro modo de producción sino de complejizar la conceptuación, motivados por la interpretación crítica de la realidad que observamos. Por ello, no dejamos de lado la teoría y el análisis marxista sino que, al contrario, lo profundizamos a la vista de los avances del siglo XX, tanto en la historiografía como en la realidad misma: la lucha de clases, en la cual es innegable el papel jugado por las mujeres y, más aún, es indiscutible que las relaciones de sexo-género

${ }^{103}$ Gadol, Kelly J., "La relación social...”, op. cit.

${ }^{104}$ Gadol, Kelly J., "La relación social...", op. cit., p. 20.

${ }^{105}$ Como representante de la corriente que sostiene la existencia de dos modos de producción podemos citar a Delphy, Christine, Por un feminismo materialista. El enemigo principal y otros textos, Barcelona, LaSal. 1970. Dentro de los trabajos que sostienen la teoría de "los sistemas duales" encontramos como principal representante a Eisenstein, Zilah, "Hacia el desarrollo de una teoría del patriarcado capitalista y el feminismo socialista", en Eisenstein, Zilah (comp.), Patriarcado capitalsta y feminismo socialista, México, Siglo XXI, 1978 . 
juegan un papel fundamental en las luchas de los trabajadores contra el capital. Y, más aún, es innegable el beneficio que comporta el trabajo doméstico (base del patriarcado) para los capitalistas.

Nuestra concepción también refleja los avances en relación con la teoría marxista y el trabajo doméstico. Sin entrar en los derroteros del debate sobre la productividad de las tareas domésticas, diremos que nosotros la incluimos en el análisis y en un lugar privilegiado y la relacionamos con el trabajo asalariado. Porque aquí se parte del supuesto de que la relación de las mujeres con el capital es fundamentalmente la de producir y reproducir la fuerza de trabajo presente y futura, de la que depende toda la explotación capitalista. Esta es la esencia de la labor doméstica y este es el trabajo para el que se prepara la mayoría de las mujeres y por el que se identifica a toda mujer.

El sistema de sexo-géneros configura relaciones asimétricas de poder que se combinan con la explotación, dando lugar a particularidades clasista-sexo-genéricas. Asimismo, estimamos que la identidad de género y la conciencia de género son parte constitutiva de la conciencia obrera femenina. Éstas están condicionadas por el lugar de la mujer y del hombre en la división sexual del trabajo, por la injerencia del patriarcado, así como por su lugar en el sistema productivo. Aquí partimos de considerar como elemento condicionante la forma específica de proletarización de la mujer, que da lugar a una experiencia, identidad y conciencia obrera femenina porque "las mujeres están proletarizadas en tanto tales [...], su destino de mujer las persigue incluso en su trabajo [productivo]". ${ }^{106}$ Como hemos dicho, la obrera no sólo es explotada, también es oprimida en tanto mujer, y esta realidad se transluce en la lectura y análisis de las fuentes históricas.

En este sentido, aquí distinguimos entre identidad y conciencia, pero en cierto sentido, estos conceptos no dejan de estar entrelazados. La identidad se forma en la interacción del individuo y la sociedad. ${ }^{107}$ Porque: "El sujeto todavía tiene un núcleo interno o esencia que es el yo real, pero dicho núcleo es formado y modificado en un continuo diálogo con los mundos culturales de afuera y las identidades que dichos mundos ofrecen". ${ }^{108}$ Aquí denominamos identidad a lo que unifica a dos o más personas, más bien a un grupo de personas, en este caso a las mujeres, en su representación de sí mismas. A partir de este concepto hemos delineado los conceptos de identidad femenina, que se define de la manera siguiente: tiene una doble base material, una es el hecho de ser mujeres, es decir su sexo, con el cual se nace, y la otra se basa en el lugar que ocupan en la división sexual del trabajo; esta identidad cruza todas las clases sociales. Por medio de la misma las mujeres se ven identificadas con el resto de las mujeres que hacen el mismo trabajo: todas son madres, cuidan de sus niños, los educan, cuidan de sus maridos, les dan de comer, hacen el trabajo doméstico y tienen el mismo sexo. Esta es la identidad femenina, la identidad de las

\footnotetext{
${ }^{106}$ Artous, Antoine, Los orígenes..., op. cit., p. 12.

${ }^{107}$ Hall, Stuart, "The rediscovery of ideology: Return of the Repressed in Media Studies", en Gurevitch, M. et. al., Culture, Society and the Media, Londres-Nueva York, Methuen, 1992.

${ }^{108}$ Hall, Stuart, "The rediscovery of ideology...," op. cit., p. 276.
} 
mujeres, que surge de la experiencia compartida con otras mujeres de llevar a cabo las mismas tareas, los mismos roles y de sufrir la misma opresión.

Por otro lado, hemos definido conciencia como todo lo que significa poder de discernimiento entre lo bueno y lo malo, conocimiento del bien y del mal, darse cuenta, percibir la realidad con conocimiento. En vistas de este análisis en particular, donde proponemos una metodología para estudiar las relaciones de género en la clase obrera, delineamos un concepto para definir el tipo de conciencia de las obreras militantes. La conciencia obrera femenina, no es igual que la identidad femenina pero están relacionada pues sin identidad femenina no hay lugar a la conciencia obrera femenina. Este concepto está definido, a nivel material, por la condición de clase de las mujeres y la división sexual del trabajo (y aquí entra la relación con la identidad) y, por otro lado, por la experiencia que hayan realizado estas mujeres con la política de las organizaciones obreras; dada la importancia que le damos al factor político-ideológico esto es fundamental. Un elemento clave de la conciencia obrera femenina es, por ejemplo, la conciencia de la doble opresión: una obrera consciente es una obrera que da cuenta de esta situación.

Ahora bien, la relación entre patriarcado y capitalismo no tiene que quedar en un nivel abstracto a nivel analítico. Como en la realidad estas relaciones aparecen sumamente imbricadas, y se ven claramente en las relaciones de clase, proponemos nuevos conceptos para analizar estas relaciones a nivel concreto. Consideramos que las mujeres, al igual que los hombres, se proletarizan en tanto tales. ${ }^{109}$ Esto es, que la experiencia particular de unas y otros, tanto en el trabajo como en la militancia, está determinada por su lugar en la división sexual del trabajo y por su pertenencia de clase. Consideramos que el capital y el patriarcado se refuerzan, se complementan y se retroalimentan mutuamente, o sea, la explotación y la opresión sexual están intrínsecamente relacionadas, y que no se puede analizar la lucha de clases sin tener en cuenta esta realidad social. Esta interrelación hace que "La experiencia que viven los hombres y las mujeres dentro de la clase obrera, [y de la burguesía] si bien confluye en la relación con los medios de producción, es diversa en lo que respecta a sus experiencias genéricas". ${ }^{110}$ La interpretación de la documentación que utilizamos en nuestras investigaciones sobre el movimiento obrero textil, ${ }^{111}$ nos ha llevado

\footnotetext{
109 Artous, Antoine, El origen..., op. cit. El planteo del autor se limita a las mujeres pero nosotros consideramos que es extensivo al género masculino.

${ }^{110}$ Norando, Verónica, "El Obrero Textil. Una interpelación clasista y generizada hacia las trabajadoras de la industria textil en Buenos Aires entre 1933 y 1946", Revista de Estudios Marítimos y Sociales, año N 4, Mar del Plata, 2011, p. 1.

${ }^{111}$ Norando, Verónica "Relaciones de género y militancia política: las obreras textiles y el comunismo entre 1936 y 1946”, Trabajos y Comunicaciones, Segunda Época, № 39, Buenos Aires, 2013, disponible en http://www.memoria.fahce.unlp.edu.ar/art_revistas/pr.6085/pr.6085.pdf; Norando, Verónica y Scheinkman, Ludmila, “"La Huelga de los Conventillos», Buenos Aires, Nueva Pompeya, 1936. Un aporte a los estudios sobre género y clase", A Contracorriente, vol. 9, $\mathrm{N}^{\circ} 1$, Universidad Estatal de Carolina del Norte, otoño de 2011, pp. 1-37; Norando, Verónica y Scheinkman, Ludmila, "Roles sexuales y lucha de clases. La huelga de las obreras de la casa Gratry, Nueva Pompeya, 1936. «Género» y «clase» en disputa”, Razón y Revolución, $\mathrm{N}^{\circ}$ 21, Buenos Aires, $1^{\circ}$ semestre de 2011, pp. 65-85.
} 
a trabajar con esta máxima metodológica pues en las fuentes podemos entrever las diferencias en las experiencias de hombres y mujeres, tanto dentro de una misma clase como en la relación con las otras clases, que tienen su base en diferencias sexuales.

Las determinaciones de género y de clase se entrecruzan y se ponen de manifiesto en los conflictos de la clase obrera contra el capital, una clase generizada que contiene a hombres y mujeres que establecen distintos tipos de relaciones en su interior y con la clase opuesta. Para desentrañar este complejo social de relaciones de clase y de sexo-género en el ámbito público (la lucha en las calles, la huelga) hemos delineado una serie de categorías analíticas para conceptualizar la forma que adquiere en el concreto social esta relación entre producción capitalista y patriarcado. Estas categorías, que facilitan la interpretación de esta relación y su enlace en la realidad histórica, son las siguientes:

- Las relaciones inter-sexo-género/inter-clase, es decir, entre personas de distinto sexo-género y de distinta clase; por ejemplo, la mujer obrera y el patrón, o viceversa (este último caso se da en contadas excepciones ya que el patrón en casi todos los casos es varón). Esta es una relación en la que se conjuga la explotación con la opresión sexual. Esta presión ejercida por el sistema patriarcal hacia el sexo-género femenino hace que se profundice la explotación capitalista. Esta relación tiene una tendencia general al antagonismo de clase agravado por el antagonismo de sexogénero, que se hace explícito tanto en el conflicto abierto (denuncias de abusos, huelgas, etc.) como en las situaciones cotidianas de tensión, como el maltrato cotidiano hacia las obreras por parte de los patrones.

- Las relaciones intra-sexo-género/inter-clase, que se dan entre personas del mismo sector sexual-genérico pero perteneciente a distintas clases sociales; por ejemplo, las relaciones entre obreros y patrones y entre obreras y patronas, donde, si bien hay una tendencia general al antagonismo por la distinta pertenencia de clase, se pueden encontrar ciertos grados de solidaridad por pertenecer al mismo sector sexualgenérico. No hay aquí opresión sexual, por eso se pueden encontrar ciertos niveles de solidaridad, sobre todo entre mujeres de distinta clase, que pueden eventualmente estar luchando ambas, por ejemplo, por el derecho al voto, la libertad sexual o el derecho a estudiar, etc. Aquí entra el factor político-ideológico, que puede unir o desunir, marcar una tendencia a la solidaridad o hacia el antagonismo.

- Las relaciones inter-sexo-género/intra-clase, que son las que se establecen entre personas de distinto sexo-género pero pertenecientes a la misma clase: las relaciones entre obreros y obreras, por un lado, y entre patrones y patronas, por el otro. Este tipo de relaciones contiene cierto nivel de opresión hacia la mujer pero mediatizado por la solidaridad de clase y, dependiendo del contexto, priman o la 
solidaridad o el antagonismo como fruto de la opresión. Pero, como el sistema sexogénero en el patriarcado asigna diferentes roles por sexo, dentro de la propia solidaridad existen diferencias irreconciliables. Con respecto a esto podemos adelantar $^{112}$ que la solidaridad inter-sexo-género/intra-clase aumenta cuando hay ascenso en la lucha de clases y hay una tendencia más marcada hacia el antagonismo cuando la lucha desciende. ${ }^{113}$

- Las relaciones intra-sexo-género/intra-clase, que son las que se establecen entre personas del mismo sexo-género y de la misma clase. Podemos poner como ejemplo las relaciones que se dan entre obreras, por un lado, y entre obreros, por el otro; y, por otra parte, entre patrones y entre patronas. Estas relaciones tienen una tendencia general hacia la solidaridad y una distribución social más horizontal del poder, pero pueden ser también de competencia o antagonismo cuando influye el factor políticoideológico.

\section{Palabras finales: a modo de balance}

A lo largo de este trabajo se ha pretendido tanto exponer los avances fundamentales para la historia del comunismo en Argentina como los exámenes que han avanzado sobre el estudio de las relaciones de género en el mundo del trabajo. Hemos intentado tender un puente entre ambos cuerpos bibliográficos enriqueciendo, de esta manera la historia social de los trabajadores y las trabajadoras. Asimismo, hemos delineado un avance sobre los que consideramos puede ser un marco teórico viable para examinar la historia del movimiento obrero y su relación con la izquierda y el comunismo en particular teniendo en cuenta las nociones de clase y de género de manera conjunta y complementaria.

Propusimos como herramientas de análisis las categorías de clase y género de manera conjunta (no separadas) para aproximarnos al examen del movimiento obrero en general como de los roles sexuales, las experiencias, la conciencia y las representaciones en particular. Hemos insistido en que debía aunarse el estudio de las relaciones de género y las de clase, pues consideramos que los roles sexuales de hombres y mujeres forman parte determinante, junto con las experiencias en las relaciones de producción, de la constitución de la conciencia. Y estas dos experiencias, las de género y las productivas son, ambas, experiencias reales, concretas, materiales, de la realidad social. La experiencia de las diferencias de género no es tan sólo una construcción y una representación social, sino que se basa sobre diferencias sexuales concretas y reales. Asimismo, la posición en las relaciones de producción tiene una materialidad propia. Género y clase están lejos de ser opuestos antagónicos, son más bien complementarios e interreproducidos. La historia social de las trabajadoras y los trabajadores se enriquece al hacer suya esta conceptualización.

\footnotetext{
${ }^{112}$ A modo de hipótesis, porque hay que hacer más estudios de caso sobre esta problemática.

${ }^{113}$ Podemos esbozar esto sólo para el caso de la clase obrera, pues no hemos estudiado lo que acontece dentro de la burguesía en este aspecto.
} 
En este trabajo se ha pretendido poner en juego esas categorías, lo que permitirá descubrir en la documentación una riqueza de relaciones, de tensiones, conflictos y solidaridades, que a menudo pasan desapercibidas en los estudios tradicionales de movimiento obrero. Como hemos documentado en varios de nuestros trabajos anteriores, ${ }^{114}$ el nivel de combatividad de las industrias no puede relacionarse con el género mayoritario de su mano de obra. Por ejemplo, la industria textil, fundamentalmente conformada por mujeres, no es ni más ni menos pasiva que otras industrias de mano de obra mayoritariamente masculina. A mediados de la década del 30, la industria textil experimenta una elevada conflictividad, como parte de algunas actividades industriales que se desarrollaron de manera acelerada (junto con la construcción, la metalurgia y la industria de la madera) en la reconversión productiva de la década y cuyos trabajadores, con la recuperación económica, se encontraron en condiciones favorables para la lucha. Sin embargo, el lugar común de una industria textil pasiva se refuerza por la escasez de estudios sobre el movimiento sindical y obrero textil y, dentro de éstos, se presta poca atención a los conflictos y la organización sindical $^{115} \mathrm{o}$, al hacerlo, no enfocan la mirada en las experiencias generizadas de los y las trabajadoras del sector. ${ }^{116}$ En un trabajo anterior, basándonos en un corpus documental diverso pudimos cuestionar estos presupuestos de la escasa conflictividad del sector textil. Hemos reconstruido las tensiones cotidianas, y también picos intensos de conflictividad, y comprobamos que, en estos conflictos, los roles sexuales y de género cumplieron un papel fundamental en la vivencia de una experiencia de clase. ${ }^{117}$

No sólo nos hemos propuesto exponer los diálogos con la historia del movimiento obrero en la Argentina de entreguerras sino que a la vez procura enriquecerla. Por una parte, al incorporar a la historia del movimiento obrero las relaciones de género y el papel del género en la construcción de las identidades y la conciencia de la mujer que trabaja. Por otra parte, al aproximar las preocupaciones de los estudios de género a la historia del movimiento obrero. En tal sentido, hemos tratado de salvar la brecha existente entre ambos cuerpos de literatura. Mientras la historiografía de movimiento obrero no se ocupó de las relaciones de género, la historia de género no se ha ocupado del movimiento obrero. En estas páginas creemos haber demostrado que es posible tender puentes y comenzar a escribir una historia generizada del movimiento obrero, que visibilice la dimensión sexuada de sus líderes y militantes y recupere la experiencia generizada de los hombres y las mujeres trabajadoras.

\footnotetext{
${ }^{114}$ Por ejemplo ver: Norando, Verónica y Scheinkman, Ludmila, “«La Huelga de los Conventillos»..., op.cit.

115 Ver, por ejemplo, Ceva, Mariela, Empresas, trabajo e inmigración..., op. cit.

${ }^{116}$ Ceruso, Diego, Comisiones internas de fábrica..., op. cit.

${ }^{117}$ Norando, Verónica y Scheinkman, Ludmila, “«La Huelga de los Conventillos»..., op.cit.
} 


\section{Referencias bibliográficas}

\section{Impresas:}

Abad de Santillán, Diego, La FORA. Ideología y trayectoria del movimiento obrero revolucionario argentino, Buenos Aires, Proyección, 1971.

Altamirano, Carlos, Peronismo y cultura de izquierda, Buenos Aires, Temas, 2001.

Anderson, Perry, Teoría, política e historia. Un debate con E.P. Thompson, Madrid, Siglo XXI, 1985.

Andújar, Andrea, "El amor en tiempos de revolución. Batallas, telenovelas, sexo y rock and roll", en Andújar, A. et al. (comps.), De minifaldas, militancias y revoluciones. Exploraciones sobre los 70 en la Argentina, Buenos Aires, Luxemburg, 2009.

Andújar, Andrea, "En demanda de lo justo: conflictos por derechos en la Patagonia petrolera" Comodoro Rivadavia, 1932", Páginas, año 6, N 12, 2014, pp. 41-67.

Arévalo, Oscar, El partido comunista, Buenos Aires, CEAL, 1983.

Artous, Antoine, Los orígenes de la opresión de la mujer, Barcelona, Fontamara, 1982.

Barrancos, Dora, "La conquista del sufragio femenino en el Río de la Plata", en Barrancos, D. y Cano, G., Historia de las mujeres en España y América Latina, t. III, Madrid, Cátedra, 2006.

Barrancos, Dora, Anarquismo, educación y costumbres en la Argentina de principios de siglo, Buenos Aires, Contrapunto, 1990.

Barrancos, Dora, Cultura, educación y trabajadores (1890-1930), Buenos Aires, CEAL, 1992.

Barrancos, Dora, La escena iluminada. Ciencias para los trabajadores (1890-1930), Buenos Aires, Plus Ultra, 1996.

Barrancos, Dora, "Moral sexual, sexualidad y mujeres trabajadoras en el período de entreguerras", en Devoto, Fernando y Madero, M., La Historia de la Vida Privada en la Argentina, Buenos Aires, Taurus, 1999.

Barrancos, Dora, Inclusión/Exclusión. Historia con mujeres, Buenos Aires, FCE, 2002.

Barrère-Maurisson, Marie, La división familiar del trabajo. La vida doble, Buenos Aires, Humánitas, 1999.

Barry, Carolina, Evita capitana. El partido peronista femenino 1949-1955, Buenos Aires, UNTREF, 2009.

Becerra, Marina, "Maternidad y ciudadanía en la Argentina de principios del siglo XX: un análisis de la autobiografía de María Rosa Oliver", A Contracorriente, vol. 10, 2013, pp. 202-218.

Belini, Claudio, "El grupo Bunge y la política económica del primer peronismo, 1943-1952", Latin American Research Review, vol. 41, No 1, 2006, California, pp. 27-50. 
Verónica Norando, Comunismo, Género y movimiento obrero: un estado de la cuestión, Izquierdas, 30, Octubre 2016:26-64

Belini, Claudio, "Monopolios, poder y política. Perón contra el grupo Bemberg, 1948-1959", Secuencia. Revista de Historia y Ciencias Sociales, N 70, Buenos Aires, 2008, pp. 103-128.

Belini, Claudio, La industria peronista, 1946-1955. Políticas públicas y cambio estructural, Buenos Aires, Edhasa, 2009.

Belini, Claudio y Rougier, Marcelo, El Estado empresario en la industria argentina. Conformación y crisis, Buenos Aires, Manantial, 2008.

Bergquist, Carlos, Los trabajadores latinoamericanos. Estudios comparativos de Chile, Argentina, Colombia y Venezuela, Colombia, Siglo XXI, 1988, pp. 158-159.

Bertúa, Paula, "Artistas y escritoras en la prensa cultural antifascista", Primeras Jornadas de Género y Trayectorias antifascistas, UNLP, 2013.

Biernat, Carolina y Ramacciotti, Karina I., Crecer y multiplicarse. La política sanitaria maternoinfantil argentina 1900-1960, Buenos Aires, Biblos, 2013.

Braverman, Henry, Trabajo y capital monopolista, México, Nuestro Tiempo, 1980.

Browarnik, Graciela y Benadiba, Laura, "Artistas militantes en el Partido Comunista argentino", Historia, Antropología y Fuentes Orales, N 37, 2007, pp. 89-99.

Burgas, Miguel, El primer diputado comunista. Año 1924, Buenos Aires, Anteo, 1985.

Camarero, Hernán, "Consideraciones sobre la historia social de la Argentina urbana en las décadas de 1920 y 1930: clase obrera y sectores populares", Nuevo Topo. Revista de historia y pensamiento crítico, $\mathrm{N}^{\circ}$ 4, 2007, pp. 35-60, Buenos Aires.

Camarero, Hernán, "Apogeo y eclipse de la militancia comunista en el movimiento obrero argentino de entreguerras. Un examen historiográfico y algunas líneas de interpretación”, en Ulianova, O. (ed.), Redes políticas y militancias. La historia política está de vuelta, Santiago, Universidad de Santiago de Chile-Ariadna, 2009, pp. 150-152.

Camarero, Hernán, Comunismo y movimiento obrero en la Argentina 1914-1943, tesis doctoral, Facultad de Filosofía y Letras, Universidad de Buenos Aires, 2008.

Camarero, Hernán, A la conquista de la clase obrera. Los comunistas y el mundo del trabajo en la Argentina, 1920-1935, Buenos Aires, Siglo XXI, 2007.

Camarero, Hernán, "Antiguas controversias, nuevos enfoques: clase obrera, sindicalismo y comunismo en la Argentina durante la primera mitad del siglo XX. Un estado de la cuestión", PolHis, año 6, Nº 11, Buenos Aires, 2013, pp. 129-146.

Camarero, Hernán, "El Partido Comunista argentino y sus políticas en favor de una cultura obrera en las décadas de 1920 y 1930”, Pacarina del Sur. Revista de pensamiento crítico latinoamericano, vol. II, México, 2011, pp. 1-31.

Camarero, Hernán, "La izquierda como objeto historiográfico. Un balance de los estudios sobre el socialismo y el comunismo en la Argentina", Nuevo Topo. Revista de historia y pensamiento crítico, $\mathrm{N}^{\circ}$ 1, Buenos Aires, 2005, pp. 77-99. 
Camarero, Hernán, "Un sindicato comunista antes del advenimiento del peronismo: el caso de la Federación Obrera Nacional de la Construcción (FONC)", Actas de las XII Jornadas Interescuelas/Departamentos de Historia, Universidad Nacional del Comahue, Bariloche, 2009.

Ceruso, Diego, Comisiones internas de fábrica. Desde la huelga de la construcción de 1935 hasta el golpe de Estado de 1943, Vicente López PIMSA-Dialektik, 2010.

Ceva, Mariela, Empresas, trabajo e inmigración en la Argentina. Casos de la Fábrica Argentina Alpargatas y Algodonera Flandria (1887-1955), Buenos Aires, Biblos, 2010.

Colman, Oscar "La industria textil y la reconversión extensiva del sector industrial argentino", Ciclos, No 2, Buenos Aires, 1992, pp. 123-155.

Contreras, Miguel, Memorias, Buenos Aires, Testimonios, 1978.

Cosse, Isabela, "La lucha por los derechos femeninos: Victoria Ocampo y la Unión Argentina de Mujeres (1936)", Revista Humanitas, año XXVI, N 34, Universidad Nacional de Tucumán, 2008, pp. 136-156.

D’Antonio, Débora y Acha, Omar, "La clase obrera «invisible»: imágenes y participación sindical de las obreras a mediados de la década de 1930 en Argentina", en Halperín, Paula y Acha, Omar (coords.), Cuerpos, géneros e identidades, Buenos Aires, Signo, 2000.

D’Antonio, Débora, "Representaciones de género en la huelga de la construcción, Buenos Aires, 1935-1936", en Gil Lozano, F.; Pita V. e Ini, G., Historia de las mujeres en la Argentina, Buenos Aires, Taurus, 2000.

Del Campo, Hugo, Sindicalismo y peronismo. Los comienzos de un vínculo perdurable, Buenos Aires, CLACSO, 1983.

Delphy, Christine, Por un feminismo materialista. El enemigo principal y otros textos, Barcelona, LaSal. 1970.

Dorfman, Adolfo, Historia de la industria Argentina, Santiago de Chile, Hispamérica, 1970, pp. 347-350.

Durruty, Celia, "La Federación Obrera de la Construcción”, en Di Tella, T.S. (coord.), Sindicatos eran los de antes, Buenos Aires, Biblos-Fundación Simón Rodríguez, 1993.

Eisenstein, Zilah, Patriarcado capitalista y feminismo socialista, México, Siglo XXI, 1980.

Eisenstein, Zilah, "Hacia el desarrollo de una teoría del patriarcado capitalista y el feminismo socialista", en Eisenstein, Zilah (comp.), Patriarcado capitalsta y feminismo socialista, México, Siglo XXI, 1978.

Engels, Frederich, El origen de la familia, la propiedad privada y el Estado, Buenos Aires, Acercándonos, 2006, p. 94.

Esquivel, Valeria , "La economía del cuidado en América Latina. Poniendo a los cuidados en el centro de la agenda", Cuadernos atando cabos; deshaciendo nudos, Programa de las Naciones Unidas para el Desarrollo, Centro Regional de América Latina y el Caribe, 2011.

Firestone, Shulamit, La dialéctica del sexo, Barcelona, Kairós, 1976. 
Verónica Norando, Comunismo, Género y movimiento obrero: un estado de la cuestión, Izquierdas, 30, Octubre 2016:26-64

Gadol, Kelly .J., "La relación social entre los sexos: implicaciones metodológicas de la historia de las mujeres", en Navarro, Marisa y Stimpson, Ccatherine, Sexualidad, género y roles sexuales, Buenos Aires, FCE, 1999.

Giordano, Verónica, "Los derechos civiles de las mujeres y la reforma del Código Civil de 1936: el acontecimiento, la coyuntura, la estructura", Terceras Jornadas de Jóvenes Investigadores del Instituto de Investigaciones Gino Germani, UBA, 2005.

Giordano, Verónica, Ciudadanas incapaces. La construcción de los derechos civiles de las mujeres en Argentina, Brasil, Chile y Uruguay en el siglo XX, Buenos Aires, Teseo, 2012.

Gutman, H. (1976), Work, Culture and Society in Industrializing America: Essays in American Working-Class and Social History, Nueva York, Kunz.

Iñigo Carrera, Nicolás, La estrategia de la clase obrera, 1936, Buenos Aires, Ediciones Madres de Plaza de Mayo, 2004.

Fava, Athos, Qué es el partido comunista, Buenos Aires, Sudamericana, 1983.

Germani, Gino, Política y sociedad en una época de transición. De la sociedad tradicional a la sociedad de masas, Buenos Aires, Paidós, 1962.

Gurbanov, Andrés y Rodríguez, Sebastián, "La huelga metalúrgica de 1942 y la crisis de la dirigencia comunista en los orígenes del peronismo", Nuevo Topo, revista de historia y pensamiento crítico, $\mathrm{N}^{\circ} 4,2007$, pp. 61-83.

Gutiérrez, Leandro y Lobato, Mirta Z., "Memorias militantes: un lugar y un pasado para los trabajadores argentinos", Entrepasados, № 3, Buenos Aires, 1992, pp. 25-49.

Hall, Catherine "La historia de Samuel y Jemima: Género y Cultura de la clase trabajadora en la Inglaterra del siglo XIX”, en Mora Vol. 19, (2), Buenos Aires, 2013.

Hall, Stuart, "The rediscovery of ideology: Return of the Repressed in Media Studies", en Gurevitch, M. et. al., Culture, Society and the Media, Londres-Nueva York, Methuen, 1992.

Hartmann, Heidi, "Un matrimonio mal avenido: hacia una unión más progresiva entre marxismo y feminismo", Zona Abierta, $\mathrm{N}^{\circ}$ 24, 1980, pp. 80-105.

Hartmann, Heidi, "Capitalismo, patriarcado y segregación de los empleos por sexos", en Borderías, Cristina; Carrasco, Cristina y Alemany, Carmen (comps.), Las mujeres y el trabajo. Rupturas conceptuales, Barcelona, Icaria-FUHEM, 1994, p. 269.

Hernández Arregui, Juan J., La formación de la conciencia nacional (1930-1960), Buenos Aires, Plus Ultra, 1960-1973.

Horowitz, Joel, "Ideologías sindicales y políticas estatales en la Argentina, 1930-1943”, Desarrollo Económico, XXIV, Buenos Aires, 1984;Iscaro, Rúbens, Historia del movimiento sindical, Buenos Aires, Fundamentos. Versión anterior: (1958), Origen y desarrollo del movimiento sindical argentino, Buenos Aires, Anteo, 1973. 
Kaplan, Temma, "Conciencia femenina y acción colectiva. El caso de Barcelona, 1910-1918", en Amelang, J.S. y Nash, Mary (comps.), Historia y Género. Las mujeres en la Europa Moderna y Contemporánea, Valencia, Alfons El Magnánim, 1990.

Kessler-Harris, A., Out to Work: A History of Wage-Earning Women in the United States, Nueva York, Oxford University Press, 1982.

Korol, Juan C. y Belini, Claudio, Historia económica de la Argentina en el siglo XX, Buenos Aires, Siglo XXI, 2012.

Lavrin, Asunción, Mujeres, Feminismo y cambio social en Argentina, Chile y Uruguay 1890-1940, Santiago de Chile, Centro de Investigaciones Diego Barros Aranda, 2005.

Lerner, Gerda, La creación del patriarcado, Barcelona, Crítica, 1990.

Lobato, Mirta Z., Historia de las trabajadoras en la Argentina (1869-1960), Buenos Aires, Edhasa, 2007.

Lobato, Mirta Z., "Rojos. Algunas reflexiones sobre las relaciones entre los comunistas y el mundo del trabajo en la década del 30", Prismas, № 6, Buenos Aires, 2002, pp. 5-15.

Lobato, Mirta Z., La vida en las fábricas. Trabajo, protesta y política en una comunidad obrera, Berisso (1904-1970), Buenos Aires, Prometeo, 2001.

Lobato, Mirta Z., "Mujeres en la fábrica. El caso de las obreras del frigorífico Armour, 19151969”, Anuario IEHS , N 5, Buenos Aires, 1990, pp. 35-62.

Lobato, Mirta Z., "Mujeres obreras, protesta y acción gremial en la Argentina: los casos de la industria frigorífica y textil en Berisso", en Barrancos, Dora, Historia y Género, Buenos Aires, CEAL, 1993.

Lobato, Mirta Z., La prensa obrera, Buenos Aires, Edhasa, 2009.

Marianetti, Benito, Argentina. Realidad y perspectivas, Buenos Aires, Platina, 1964.

Marotta, Sebastián, El movimiento sindical argentino. Su génesis y desarrollo, t. III, Buenos Aires, Lebera, 1975.

Marx, Karl, "Prólogo a la contribución a la crítica de la economía política", Buenos Aires, Comunicaciones, 1980.

Marx, Karl, Miseria de la filosofía, Buenos Aires, América, 1969.

Mastrángelo, Mariana, Rojos en la Córdoba obrera, 1930-1943, Buenos Aires, Imago Mundi, 2011.

McGee Deutsch, Sandra, "Argentine Women Against Fascism: The Junta de la Victoria, 19411947”, Politics, Religion and Ideology, vol. 13, N², 2012, pp. 221-236.

McGee Deutsch, Sandra, "Mujeres, antifascismo y democracia: la Junta de la Victoria, 1941-1947", Anuario IEHS, $\mathrm{N}^{\circ}$ 28, Buenos Aires, 2013, pp. 157-175. 
Montgomery, David [1988], The fall of the house of labour, Cambridge University Press, 2005; Baron, Aba (ed.), Work Engendered: Toward a New History of American Labor, Ithaca, Cornell University Press, 1991.

Murmis Miguel y Portantiero, Juan C., Estudios sobre los orígenes del peronismo, Buenos Aires, Siglo XXI, 1971.

Nari, María M.A. Políticas de maternidad y maternalismo político. Buenos Aires, 1890-1940, Buenos Aires, Biblos, 2004.

Nari, Marcela, "El movimiento obrero y el trabajo femenino. Un análisis de los congresos obreros durante el período 1890-1921", en Knecher, L. y Panaia, M. (comps.), La otra mitad del país. La mujer en la sociedad argentina, Buenos Aires, CEAL, 1994.

Navarro, Marisa, Evita, Buenos Aires, Planeta; Bianchi, S. y Sanchís, N. (1988), El Partido Peronista Femenino, Buenos Aires, CEAL, 1994.

Norando, Verónica, "El Obrero Textil. Una interpelación clasista y generizada hacia las trabajadoras de la industria textil en Buenos Aires entre 1933 y 1946", Revista de Estudios Marítimos y Sociales, año $\mathrm{N}^{\circ}$ 4, Mar del Plata, 2011.

Norando, Verónica y Scheinkman, Ludmila, "«La Huelga de los Conventillos», Buenos Aires, Nueva Pompeya, 1936. Un aporte a los estudios sobre género y clase”, A Contracorriente, vol. 9, $\mathrm{N}^{\circ}$ 1, Universidad Estatal de Carolina del Norte, otoño de 2011, pp. 1-37.

Norando, Verónica y Scheinkman, Ludmila, "Roles sexuales y lucha de clases. La huelga de las obreras de la casa Gratry, Nueva Pompeya, 1936. "Género» y «clase» en disputa", Razón y Revolución, $\mathrm{N}^{\circ} 21$, Buenos Aires, $1^{\circ}$ semestre de 2011, pp. 65-85.

Oddone, Jacinto, Historia del socialismo argentino, Buenos Aires, CEAL, 1983.

Offen, Karen, Escribir la historia de las mujeres: Perspectivas Internacionales, Indiana University Press, 1991.

Palermo, Silvana, “¿Trabajo masculino protesta femenina? La participación de la mujer en la gran huelga ferroviaria de 1917”, en Bravo, M.C.; Gil Lozano F. y Pita, V. (comps.), Historia de luchas, resistencias y representaciones. Mujeres en la Argentina. Siglos XIX y XX, Tucumán, Universidad de Tucumán, 2007.

Pascucci, Silvina, Costureras, monjas y anarquistas. Trabajo femenino, Iglesia y lucha de clases en la industria del vestido (Buenos Aires 1890-1940), Buenos Aires, Razón y Revolución, 2007.

Pateman, Carol, El Contrato Sexual, México, Anthropos, 1995.

Paso, Leonardo, Historia de los partidos políticos en la Argentina (1900-1930), Buenos Aires, Directa, 1983.

Pérez, Inés, "Un «régimen especial» para el servicio doméstico. Tensiones entre lo laboral y lo familiar en la regulación del servicio doméstico en la Argentina, 1926-1956", en El trabajo doméstico entre regulaciones formales e informales. Miradas desde la historia y la sociología, IDES, Serie proyectos de investigación, 2015. 
Perrig, Sara, "Alcira de la Peña, los derechos políticos femeninos y las elecciones de 1951", Serie Cuadernos del IDES, N ${ }^{\circ}$ 27, Buenos Aires, Instituto de Desarrollo Económico y Social, 2013, pp. 3-20.

Peter, José, Crónicas proletarias, Buenos Aires, Esfera, 1968.

Pita, Valeria S., "Estudios de género e historia. Situación y perspectivas", Mora, $\mathrm{N}^{\mathrm{o}}$ 4, Buenos Aires, 1998, pp. 72-82.

Puiggrós, Rodolfo, Las izquierdas y el problema nacional, Buenos Aires, Cepe, 1973.

Queirolo, Graciela, "Las mujeres y los niños en el mercado de trabajo urbano (Buenos Aires, 18901940)", en Recalde, Hector E. (coord.), Señoras, universitarias y mujeres (1910-2010), Buenos Aires, Grupo Editor Universitario, 2010, pp. 17-37.

Queirolo, Graciela, "La mujer en la sociedad moderna a través de los escritos de Victoria Ocampo (1935-1953)", en Alicia Salomone et al. (eds.), Modernidad en otro tono. Escritura de mujeres latinoamericanas: 1920-1950, Santiago de Chile, Cuarto Propio, 2004.

Ramacciotti, Karina I., "Una mirada sobre el estudio de la política social en la Argentina", Nuevo Topo. Revista de historia y pensamiento crítico, $\mathrm{N}^{\circ} 1$, Buenos Aires, 2005.

Ramacciotti, Karina I., "Las trabajadoras en la mira estatal: Propuestas de reforma de la Caja de Maternidad (1934-1955)", Trabajos y Comunicaciones, 2º́poca, UNLP, 2005.

Ramacciotti, Karina I., "De la culpa al seguro. La ley de accidentes de trabajo, 1915-1955”, Mundos do Trabalho, vol. 3, N 5, ANPUH, 2011, pp. 266-284.

Ramos, Jorge A., El Partido Comunista en la política argentina, Buenos Aires, Coyoacán, 1962.

Rocchi, Fernando, "Concentración de capital, concentración de mujeres. Industria y trabajo femenino en Buenos Aires 1890-1930", en Gil Lozano, Fernanda., Pita, Valeria S. e Ini, María G. (comps.), Historia de las mujeres en la argentina, t. II: Siglo XX, Buenos Aires, Taurus, 2000.

Rodríguez Enríquez, Corina, "La economía del cuidado: un aporte para el estudio de políticas públicas", Documento de Trabajo, Buenos Aires, Centro Interdisciplinario para el Estudio de Políticas Públicas, 2005, pp. 1-19.

Rodríguez, Florencia, “Masculinidad Clasista? Aportes a un debate abierto en el campo de la historia latinoamericana contemporánea”, Fazendo Genero 2010, Diasporas, Diversidades e Deslocamentos, UFSC, Florianópolis, agosto de 2010.

Sazbón, José, "Dos caras del marxismo inglés. El intercambio Thompson-Anderson", Punto de Vista. Revista de cultura, año X, No 29, Buenos Aires, abril de 1987, pp. 11-25.

Schiavi, Marcos, "La dinámica sindical durante los dos primeros gobiernos peronistas (1946-1955). El caso de las industrias metalúrgica y textil en la ciudad de Buenos Aires y sus alrededores", tesis de doctorado, Universidad de Buenos Aires-Université París 8, 2011.

Scott, Joan W., "El género: una categoría útil para el análisis histórico", en Amelang, J. y Nash, M. (coords.), Historia y género: las mujeres en la Europa moderna y contemporánea, Valencia, Alfons el Magnánim, 1990. 
Scott, Joan W., "Prefacio a Gender and politics of history", Cuadernos Pagu, $\mathrm{N}^{\circ}$ 3, Universidad Estadual de Campinas, 1994, pp. 12-13.

Scott, Joan W., "La mujer trabajadora en el siglo XIX", en Duby, G. y Perrot, M., Historia de las mujeres en Occidente, t. 4: El siglo XIX, Madrid, Taurus, 2000.

Thompson, Edward P. La formación de la clase obrera en Inglaterra, Barcelona, Crítica, 1989.

Thompson, Edward P., "Algunas observaciones sobre clase y «falsa conciencia»", Cuadernos de teoría e historia de la historiografía, № 1, 1987, pp. 27-32.

Thompson, Edward P., Miseria de la teoría, Barcelona, Crítica, 1981, p. 19.

Thompson, Dorothy "Las mujeres y la radicalidad política en el siglo XIX: una dimensión ignorada", en Mora, Vol. 19, (2), Buenos Aires, 2013.

Tilly, Louise A., "Género, historia de las mujeres e historia social", Cuadernos Pagu, $\mathrm{N}^{\circ}$ 3, Universidad Estadual de Campinas, 1994, pp. 29-62.

Torre, Juan C., La vieja guardia sindical y Perón. Sobre los orígenes del peronismo, Buenos Aires, Razón y Revolución, 1990.

Valobra, Adriana, "Formación de cuadros y frentes populares: las mujeres en el Partido Comunista de Argentina, 1935-1951", Revista Izquierdas, № 23, Santiago de Chile, 2015, pp. 127-156.

Valobra, Adriana, Mujeres en espacios bonaerenses, La Plata, Edulp, 2009.

Valobra, Adriana, "Algunas consideraciones acerca de la historia de las mujeres y género en Argentina", Nuevo Topo. Revista de historia y pensamiento crítico, $\mathrm{N}^{\circ}$ 1, Buenos Aires., 2005, pp. 77-79.

Valobra, Adriana, Del hogar a las urnas. Recorridos de la ciudadanía política femenina. Argentina 1946-1955, Buenos Aires, Prohistoria, 2010.

Valobra, Adriana, "La UMA en marcha. El Partido Comunista Argentino y las tradiciones y estrategias de movilización social en el primer gobierno peronista: el caso de la Unión de Mujeres Argentinas (UMA)", Canadian Journal of Latin American and Caribbean Studies, vol. 30, $\mathrm{N}^{\circ}$ 60, Montreal, Universitè de Québec, 2005, pp. 155-183.

Valobra, Adriana, "Partidos, tradiciones y estrategias de movilización social: de la Junta de la Victoria a la Unión de Mujeres de la Argentina", Prohistoria, año IX, Nº 9, Rosario, 2005, pp. 6782.

Weinstein, Barbara, "La investigación sobre identidad cultural y ciudadanía en Estados Unidos: de la nueva historia social a la nueva historia cultural", Fronteras de la historia, vol. 5, Bogotá, 2000, pp. 73-91.

Zemon Davis, Nathaly, "Las formas de la historia social", Historia Social, $\mathrm{N}^{\circ}$ 10, Valencia, primavera-verano, 1991, pp. 177-184. 


\section{Electrónicas:}

Di Tella, Torcuato S., "La Unión Obrera Textil. 1930-1945”, Desarrollo Económico, N 129, Buenos Aires, 1993, pp. 110-136, 3, disponible en http://repositoriorecursosdownload.educ.ar/repositorio/Download/file?file_id=b8ba91b2-7a09-11e1-82f0-ed15e3c494af

Guerra Luciana A., El feminismo socialista de Flora Tristán: Una aproximación a la sabiduría de una paria, trabajo final de grado, Universidad Nacional de La Plata, Facultad de Humanidades y Ciencias de la Educación, 2015, disponible en

http://www.memoria.fahce.unlp.edu.ar/tesis/te.1109/te.1109.pdf; fecha de consulta: 3 de enero de 2015.

Norando, Verónica "Relaciones de género y militancia política: las obreras textiles y el comunismo entre 1936 y 1946”, Trabajos y Comunicaciones, Segunda Época, № 39, Buenos Aires, 2013, disponible en

http://www.memoria.fahce.unlp.edu.ar/art_revistas/pr.6085/pr.6085.pdf;

Queirolo, Ggraciela, "Mujeres que trabajan: una revisión historiográfica del trabajo femenino en la Ciudad de Buenos Aires (1890-1940)", Nuevo Topo. Revista de historia y pensamiento crítico, $\mathrm{N}^{\circ}$ 3, Buenos Aires, 2006, pp. 29-49, disponible en

http://www.academia.edu/12934730/Mujeres_que_trabajan_una_revisi\%C3\%B3n_historiogr\%C3\% A1fica_del_trabajo_femenino_en_la_ciudad_de_Buenos_Aires_1890-1940; fecha de consulta: 10 de noviembre de 2015.

Queirolo, Graciela, "El mundo de las empleadas administrativas: perfiles laborales y carreras individuales (Buenos Aires, 1920-1940)", Trabajos y Comunicaciones, $N^{\circ} 34$, Buenos Aires, 2008, disponible en

http://www.trabajosycomunicaciones.fahce.unlp.edu.ar/article/viewFile/TYC2008n34a07/pdf_116

Queirolo, Graciela, "Dora Barrancos, Inclusión/Exclusión. Historia con mujeres, Buenos Aires, FCE, 2002, 159 p.", Nuevo Mundo Mundos Nuevos, 2005, disponible en https://nuevomundo.revues.org/338; fecha de consulta: 5 de febrero de 2016.

Santa Cruz, Claudia, "El partido comunista ante el problema del transporte en 1943: posisión política, acción gremial y nuevas alianzas en el seno del transporte de autos colectivos", Dossier "Nuevas aproximaciones historiográficas sobre el vínculo del PC y el movimiento obrero, 2012, disponible en http://historiapolitica.com/datos/biblioteca/pcmovo_santacruz.pdf; fecha de consulta: 8 de julio de 2015 . 